\title{
Effect of different modified atmospheric packaging (MAP) gaseous combinations on Campylobacter and the shelf-life of chilled poultry fillets
}

Meredith, H., Valdramidis, V., Rotabakk, B. T., Sivertsvik, M., McDowell, D. A., \& Bolton, D. J. (2014). Effect of different modified atmospheric packaging (MAP) gaseous combinations on Campylobacter and the shelf-life of chilled poultry fillets. Food Microbiology, 44, 196-203.

Link to publication record in Ulster University Research Portal

Published in:

Food Microbiology

Publication Status:

Published (in print/issue): 01/01/2014

\section{Document Version}

Publisher's PDF, also known as Version of record

\section{General rights}

Copyright for the publications made accessible via Ulster University's Research Portal is retained by the author(s) and / or other copyright owners and it is a condition of accessing these publications that users recognise and abide by the legal requirements associated with these rights.

\section{Take down policy}

The Research Portal is Ulster University's institutional repository that provides access to Ulster's research outputs. Every effort has been made to ensure that content in the Research Portal does not infringe any person's rights, or applicable UK laws. If you discover content in the Research Portal that you believe breaches copyright or violates any law, please contact pure-support@ulster.ac.uk. 


\title{
Effect of different modified atmospheric packaging (MAP) gaseous combinations on Campylobacter and the shelf-life of chilled poultry fillets
}

\author{
H. Meredith ${ }^{\mathrm{a}, \mathrm{d}}$, V. Valdramidis ${ }^{\mathrm{b}}$, B.T. Rotabakk ${ }^{\mathrm{c}}$, M. Sivertsvik $^{\mathrm{c}}$, D. McDowell $^{\mathrm{d}}$, \\ D.J. Bolton ${ }^{\mathrm{a}, *}$ \\ ${ }^{\text {a }}$ Food Safety Department, Teagasc Food Research Centre, Ashtown, Dublin 15, Ireland \\ ${ }^{\mathrm{b}}$ Department of Food Studies and Environmental Health, Faculty of Health Sciences, Msida MSD 2080, University of Malta, Malta \\ ${ }^{\mathrm{c}}$ Nofima, Norwegian Institute of Food, Fisheries and Aquaculture Research, Department of Processing Technology, Stavanger, Norway \\ ${ }^{\mathrm{d}}$ Food Microbiology Research Unit, School of Health and Life Sciences, University of Ulster, Jordanstown, Newtownabbey, Co. Antrim, Northern Ireland, UK
}

\section{A R T I C L E I N F O}

\section{Article history:}

Received 13 December 2013

Received in revised form

14 March 2014

Accepted 10 June 2014

Available online 18 June 2014

\section{Keywords:}

Campylobacter

Poultry

Modified atmospheric packaging

Shelf-life

\begin{abstract}
A B S T R A C T
Studies were undertaken to investigate the effect of different modified atmospheric packaging (MAP) gaseous combinations on Campylobacter and the natural microflora on poultry fillets. Skinless chicken fillets were stored in gaseous mixtures of $10 \%, 30 \%, 50 \%, 70 \%$ and $90 \% \mathrm{CO}_{2}$ balanced with $\mathrm{N}_{2}, 80: 20 \%$ $\mathrm{O}_{2}: \mathrm{N}_{2}$ and $40: 30: 30 \% \mathrm{CO}_{2}: \mathrm{O}_{2}: \mathrm{N}_{2}$ and control conditions (air) at $2{ }^{\circ} \mathrm{C}$. Samples were analysed periodically for (previously inoculated) Campylobacter, total viable counts (TVC) (mesophiles), TVC (psychrophiles), Enterobacteriaceae, Pseudomonas and lactic acid bacteria (LAB) over 17 days of storage. The carbon dioxide solubility was determined by monitoring the changes in the headspace volume over time using a buoyancy technique and performing calculations based on volumetric measurements and the Henry's constant. Henry's constant was also used to estimate the oxygen solubility in the chicken fillets. The presence of $\mathrm{O}_{2}$ in the MAP gaseous mixtures increased the rate of Campylobacter decline on poultry fillets but in general the counts obtained in aerobic versus anaerobic packs were not significantly $(P>0.05)$ different. $\mathrm{CO}_{2}$ inhibited the growth of TVC, TEC, LAB and Pseudomonas but only at MAP gaseous combinations containing $50-90 \% \mathrm{CO}_{2}$ where concentrations of up to $2000 \mathrm{ppm} \mathrm{CO}_{2}$ were recorded in the fillets after 5 days. Under these conditions a shelf-life in excess of 17 days at $2{ }^{\circ} \mathrm{C}$ was obtained. Although, dissolved $\mathrm{O}_{2}$, at levels of $33 \mathrm{ppm}$ in $80: 20 \% \mathrm{O}_{2}: \mathrm{N}_{2}$ packs after 3 days, reduced Campylobacter, it also favoured the growth of the other microbes on the chicken. The optimum gaseous mixture for achieving the combined objectives of reducing Campylobacter and extending shelf was therefore 40:30:30 $\mathrm{CO}_{2}: \mathrm{O}_{2}: \mathrm{N}_{2}$, which achieved a shelf-life in excess of 14 days.
\end{abstract}

() 2014 Elsevier Ltd. All rights reserved.

\section{Introduction}

Poultry is an important source of Campylobacter, the primary cause of bacterial gastroenteritis in the developed world. The most recent European Food Safety Authority (EFSA) baseline survey reported a 98.3\% Campylobacter prevalence on raw poultry carcasses in Ireland (EFSA, 2010). Although, biosecurity measures on broiler farms and interventions throughout the slaughter plant are continually being addressed, levels of Campylobacter contamination remain high (Haughton et al., 2010). To date, much research

\footnotetext{
* Corresponding author. Tel.: +353 1 8059539; fax: +353 18059550 .

E-mail address: declan.bolton@teagasc.ie (D.J. Bolton).
}

has focused on pre-harvest and processing interventions with few investigations on the use of modified atmospheric packaging (MAP) to control Campylobacter and extend shelf-life (Byrd et al., 2011). Furthermore, in the few studies that have been published, no data is provided on the amount of oxygen $\left(\mathrm{O}_{2}\right)$ and carbon dioxide $\left(\mathrm{CO}_{2}\right)$ dissolved in the product.

Poultry is a highly perishable food which deteriorates after 4-10 days post slaughter even under chilled conditions (Jimenez et al., 1997; Patsias et al, 2006a,b). MAP is a well established method to extend the shelf-life of fresh and processed chilled foods (Charles et al., 2006; Devlieghere et al., 1998; Devlieghere and Debevere, 2000; Rotabakk et al., 2010) and is used to prolong the shelf-life of poultry fillets by suppressing aerobic spoilage bacteria such as Pseudomonas (Sade et al., 2013). However, psychrotrophic 
facultative anaerobic bacteria such as LAB, that are less sensitive to $\mathrm{CO}_{2}$, will grow under MAP conditions. Enterobacetriaceae will also grow in the presence of $\mathrm{CO}_{2}$ but to a lesser extent than LAB (Sade et al., 2013). Data on the effect of different MAP gaseous combinations on the survival of Campylobacter on poultry fillets is limited (Byrd et al., 2011) and the optimum gaseous combination in terms of the elimination of Campylobacter while maximising shelf-life is unknown (Patsias et al., 2006b). In theory high $\mathrm{O}_{2}$ concentrations should inhibit Campylobacter spp. which are microaerobic and grow optimally at about $5 \% \mathrm{O}_{2}$ and this has been demonstrated by Byrd et al. (2011). However, $\mathrm{O}_{2}$ supports the growth of other bacteria including spoilage organisms like Pseudomonas and lactic acid bacteria (LAB) which produce slime, souring and/or off-odours when counts reach $10^{7-8} \mathrm{CFU} / \mathrm{g}$ (Nychas et al., 2008; Charles et al., 2006).

MAP is a non-thermal method of food preservation that uses 3 gases; nitrogen $\left(\mathrm{N}_{2}\right)$, Oxygen $\left(\mathrm{O}_{2}\right)$ and carbon dioxide $\left(\mathrm{CO}_{2}\right) . \mathrm{N}_{2}$ is an inert gas with no antimicrobial activity but the anoxic atmospheres created when using this gas will select for anaerobic, aerotolerant Lactobacilli (Thippareddi and Phebus, 2007). Its primary function is as a filler and to prevent pack collapse. $\mathrm{O}_{2}$ inhibits the growth of anaerobic bacteria but the principle, antimicrobial effect is due to the presence of $\mathrm{CO}_{2}$. Although the use of $\mathrm{CO}_{2}$ enriched modified atmospheres to extend shelf-life has been well documented (Gill et al., 1990), data for use in food safety risk assessments and shelf-life modelling studies are scarce. $\mathrm{CO}_{2}$ readily passes through the bacterial cell membranes and four possible bacteria related mechanisms for inhibition have been suggested including: [1] the formation of carbonic acid within the bacterial cell resulting in decreased intracellular $\mathrm{pH}$ and reduced enzyme activity (Wolfe, 1980); [2] specific inhibition of decarboxylating enzymes (King and Nagel, 1975); [3] non-specific inhibition of susceptible nondecarboxylating enzymes (Ranson et al., 1960) and [4] alteration of membrane properties that inhibits membrane functions (Sears and Eisenberg, 1961).

Regardless, the bacteriostatic effect of $\mathrm{CO}_{2}$ within MAP is primarily influenced by $\mathrm{CO}_{2}$ absorption into the food and several studies have measured the solubility of $\mathrm{CO}_{2}$ in perishable foods (Jakobsen and Bertelsen, 2004, 2006; Jakobsen and Risbo, 2009; Rotabakk et al., 2010), although poultry data is lacking. Different methods have been used in these studies including a comparison of initial and final pressures (Devlieghere and Debevere, 2000) and modified titration (Gill, 1988) but continuous monitoring requires a non-destructive approach such as the buoyancy force based method (Rotabakk et al., 2007). A minimum head space concentration of $20-30 \%$ is required to achieve bacterial inhibition (Stiles, 1991 a,b) and the poultry industry therefore typically uses $40-100 \%$ $\mathrm{CO}_{2}$ balanced with $\mathrm{N}_{2}$.

The objectives of this study were to investigate the effect of different gaseous combinations on inoculated Campylobacter and the natural microflora on chilled poultry fillets and to characterise the different MAP treatments in terms of dissolved carbon dioxide and oxygen in chicken fillets throughout a given storage period.

\section{Materials and methods}

\subsection{Culture preparation}

Five Campylobacter strains, two strains of Campylobacter jejuni (1136DF, $11168 \mathrm{NCTC}$ ) and three strains of Campylobacter coli (2124GF, 323BC, 1354 DF) were used in this study. Strains were stored at $-80{ }^{\circ} \mathrm{C}$ on ceramic beads (TSC, Heywood, UK). Inocula were prepared separately by aseptically transferring a bead from the stock cultures to $30 \mathrm{ml}$ Hunts broth (Nutrient broth (Oxoid, Basingstoke, UK) and Yeast Extract (Oxoid, Basingstoke, UK), 5\% lysed horse blood and 0.4\% Campylobacter growth supplement FBP) and incubating at $42{ }^{\circ} \mathrm{C}$ for $48 \mathrm{~h}$ under microaerobic conditions (Biomerieux, Marcy l'Etoile, France). From the resultant suspension, $1 \mathrm{ml}$ of each was used to inoculate $5 \times 100 \mathrm{ml}$ Hunts broth and these were incubated under microaerobic conditions at $42{ }^{\circ} \mathrm{C}$ for a further $24 \mathrm{~h}$. Cells were recovered by centrifugation (10 $\mathrm{min}$ at $2655 \mathrm{~g}$ ), washed 3 times in maximum recovery diluent (MRD; Oxoid Basingstoke, UK), resuspended in $10 \mathrm{ml}$ MRD, mixed and the volume of MRD increased to $500 \mathrm{ml}$, which gave a cell suspension containing approximately $8 \log _{10} \mathrm{CFU} / \mathrm{ml}$. Cell suspension concentrations were assessed by preparing 10 fold dilution series and plating $0.1 \mathrm{ml}$ dilutions onto modified charcoal cefoperazone deoxycholate agar medium (mCCDA, Oxoid, Basingstoke, UK) plates in duplicate.

\subsection{Sample preparation}

Three hundred and forty chicken breast fillets were collected from the poultry processing plant immediately after chilling. The samples were transported to the laboratory at $4 \pm 1{ }^{\circ} \mathrm{C}$. They were then divided into 3 groups, group 1 and 2 each containing 160 fillets and group 3 containing 20. Group 1 and 3 fillets remained uninoculated while the 160 fillets in group 2 were inoculated using the Campylobacter cocktail prepared above. Each fillet was independently immersed in the freshly prepared Campylobacter suspension for $15 \mathrm{~s}$ and left at room temperature for $15 \mathrm{~min}$ to allow for bacteria adhesion. Using this method each fillet was inoculated with approximately $4.5 \log _{10}$ Campylobacter per g. The weights of all samples were taken prior to packaging.

Groups 1 and group 2 fillets were each divided into 8 groups (labelled $\mathrm{A}$ to $\mathrm{H}$ ) of 20 samples each. Group $1 \mathrm{~A}$ and $2 \mathrm{~A}$ samples were used as the control and packaged in air. Groups $\mathrm{B}$ to $\mathrm{H}$ had the following gaseous combinations; (B) $90 / 10 \%\left(\mathrm{~N}_{2}: \mathrm{CO}_{2}\right)$, (C) $70: 30 \%$ $\left(\mathrm{N}_{2}: \mathrm{CO}_{2}\right)$ (D) $50: 50 \%\left(\mathrm{~N}_{2}: \mathrm{CO}_{2}\right)$ (E) $30: 70 \%\left(\mathrm{~N}_{2}: \mathrm{CO}_{2}\right)$ (F) $10: 90 \%$ $\left(\mathrm{N}_{2}: \mathrm{CO}_{2}\right)(\mathrm{G}) 80: 20 \%\left(\mathrm{O}_{2} / \mathrm{N}_{2}\right)$ or $(\mathrm{H})$ 40:30:30\% $\left(\mathrm{CO}_{2} / \mathrm{O}_{2} / \mathrm{N}_{2}\right)$. At times $1,2,3,4,5,7,9,11,14$ and 17 days 2 samples were removed from groups 1 and 2 (eg. $1 \mathrm{~A} 2 \mathrm{~A}, 2 \mathrm{~B}$, etc.), the gaseous composition was analysed (see Section 2.6) prior to microbiological analysis (see Section 2.4). Group 3, two packs were removed from each group immediately after packaging and used repeatedly for volumetric analysis over the 17 days (see Section 2.5).

\subsection{Packaging and storage}

All samples were packed into EVOH semi-rigid trays $110 \times 150 \times 46 \mathrm{~mm}$ (Versatile Packaging, Ireland), gases were pumped in and heat sealed using a MECAPAC 500 MAP machine (Mecaplastic Bagnolet, France). The trays (had an oxygen transmission rate of $0.15 \mathrm{~cm}^{2} /$ Pck d bar) were covered with a $76 \mathrm{~mm}$ antifog high barrier film with an oxygen transmission rate of $0.8 \mathrm{ml} /$ $\mathrm{m}^{2} / 24 \mathrm{~h}$ (at $23{ }^{\circ} \mathrm{C}, 0 \% \mathrm{RH}$ ) and packed in a refrigerated room environment $\left(<4{ }^{\circ} \mathrm{C}\right)$. During packaging the air was removed and flushed with food grade gas mixtures of $\mathrm{CO}_{2}$ and $\mathrm{N}_{2}(10 \%, 30 \%, 50 \%$, $70 \%, 90 \% \mathrm{CO}_{2}$, balanced with $\mathrm{N}_{2}$ ), $80: 20 \% \mathrm{O}_{2}: \mathrm{N}_{2}$ and also $40: 30: 30 \%$ $\mathrm{CO}_{2}: \mathrm{O}_{2}: \mathrm{N}_{2}$ (BOC, Ireland). The gas/product ratio was $5: 1$. All samples were stored at $2{ }^{\circ} \mathrm{C}$ without light exposure for up to 17 days.

\subsection{Microbiological analysis}

All chicken samples in group 1, i.e., uninoculated control group, were analysed immediately for Campylobacter spp., total viable counts (TVC (mesophiles, $30^{\circ} \mathrm{C}$ )), TVC (psychrophiles, $6.5^{\circ} \mathrm{C}$ ), total Enterobacteriaceae counts (TEC), lactic acid bacteria (LAB) and Pseudomonas spp. and on days 1, 2, 3, 4, 5, 7, 9, 11, 14 and 17. Group 2 samples were only analysed for Campylobacter spp. For microbial 
enumeration, approximately $10 \mathrm{~g}$ of chicken fillet samples $\left(3 \times 3 \mathrm{~cm}^{2}\right.$ of the surface and $1 \mathrm{~cm}$ thickness) were weighed out aseptically, transferred to a sterile stomacher bag with $90 \mathrm{ml}$ MRD (Oxoid) and pulsified for $15 \mathrm{~s}$ (Lab Blender 400 series, Steward Medical, London, UK). Ten fold serial dilutions of chicken homogenate were prepared and 1.0 or $0.1 \mathrm{ml}$ was spread on the surface of the appropriate media for enumeration of the different bacteria.

Campylobacter spp. counts were enumerated on Campylobacter blood-free agar base (modified charcoal cefoperazone deoxycholate agar [mCCDA] Oxoid) and incubated at $42^{\circ} \mathrm{C}$ for $48 \mathrm{~h}$ under microaerobic conditions (Biomerieux, Marcy l'Etoile, France) (5\% $\mathrm{O}_{2}, 10 \% \mathrm{CO}_{2}$ and $85 \% \mathrm{~N}_{2}$ ) in duplicate. Aerobic TVC mesophiles and psychrophiles were both enumerated on standard plate count agar (SPCA, Oxoid, Basingstoke, UK) incubated at $30{ }^{\circ} \mathrm{C}$ for $72 \mathrm{~h}$ and $6.5{ }^{\circ} \mathrm{C}$ for 10 days, respectively. Total enterobacteriaceae counts (TEC) were enumerated on violet red bile glucose agar (VRBGA, Oxoid, Basingstoke, UK) after incubation at $37{ }^{\circ} \mathrm{C}$ for $24 \mathrm{~h}$. Lactic acid bacteria (LAB) were enumerated on De Man Rogasa Sharpe agar (MRS, Oxoid, Basingstoke, UK) following incubation at $30{ }^{\circ} \mathrm{C}$ for $72 \mathrm{~h}$. Finally, Pseudomonas spp. were enumerated on cetrimide agar with selective supplement (CFC, Oxoid, Basingstoke, UK) after incubation at $25^{\circ} \mathrm{C}$ for $48 \mathrm{~h}$.

\subsection{Headspace volume assessment}

The headspace volumes were measured on each of the test days by submerging the packages with the product under water and measuring the resultant force with a texture analyser (Stable Micro System Ltd., TAXT2i Texture Analyser, UK), as described by Rotabakk et al (2007). Briefly, the package was submerged, upside down to avoid capture of air bubbles, at a rate of $2 \mathrm{~mm} / \mathrm{s}$ for $15 \mathrm{~s}$, and held submerged for $30 \mathrm{~s}$ to stabilize. An average of buoyancy measurements taken at $26 \mathrm{~s}, 28 \mathrm{~s}$ and $30 \mathrm{~s}$ were used in Equation (1). Atmospheric pressure at the specific time and sample date were collected from the Irish Meteorological Service and the pressures were adjusted accordingly (Glasnevin Hill, Dublin, Ireland), www. met.ie.

The package headspace volume changes were then used to calculate the absorbed $\mathrm{CO}_{2}$ concentration in the product (Rotabakk et al., 2007)

$C_{\mathrm{CO}_{2}}^{t=\infty}=\frac{1000 \cdot P \cdot\left(V_{g}^{t=o}-V_{g}^{t=i}\right) \cdot M w_{C_{2}}}{R \cdot T \cdot W_{f}}$

Where $C_{\mathrm{CO}_{2}}^{t=\infty}$ is the total absorbed $\mathrm{CO}_{2}$ (ppm) in the product, $P$ is the absolute gas pressure (Pa), $V_{g}^{t=0}$ is initial the gas volume $\left(\mathrm{m}^{3}\right), V_{g}^{t=i}$ is the gas volume at sampling time $i\left(\mathrm{~m}^{3}\right), M w_{\mathrm{CO}_{2}}$ is the molecular weight of $\mathrm{CO}_{2}(44.01 \mathrm{~g} / \mathrm{mol}), R$ is the gas constant $\left(8.314 \mathrm{~J} / \mathrm{mol} / \mathrm{K}^{-1}\right)$, $T$ is the absolute temperature $(\mathrm{K})$ and $W_{f}$ is the weight of product (kg). After 3-4 days MA packages has shown to reach equilibrium (Sivertsvik et al., 2004; Sivertsvik and Jensen, 2005; Rotabakk et al., 2010; Fletcher et al., 2004), hence after day 3 the total amount of absorbed $\mathrm{CO}_{2}$ was calculated according to Henry's law and the head space gas analysis.

\subsection{Headspace gas analysis}

The headspace gas composition $\left(\mathrm{O}_{2}\right.$ and $\left.\mathrm{CO}_{2}(\mathrm{ml} / 100 \mathrm{ml})\right)$ in all packs was measured immediately after packing and at each sampling time using an oxygen and carbon dioxide analyser (Checkmate 9900 analyser, PBI-Dansensor, Ringsted, Denmark). An aliquot of the headspace gas was collected with a syringe after piercing the film cover. According to Henry's law, once the package has reached equilibrium, the amount of surrounding $\mathrm{CO}_{2}$ in the headspace is proportional to the absorbed $\mathrm{CO}_{2}$ in the product (Rotabakk et al., 2010):

$P_{\mathrm{CO}_{2}}^{t=i}=H_{\mathrm{CO}_{2, p}} \times \mathrm{C}_{\mathrm{CO}_{2}}^{t=i}$

Where $P_{\mathrm{CO}_{2}}^{t=i}$ is the partial pressure of $\mathrm{CO}_{2}$ in the headspace (Pa), $\mathrm{H}_{\mathrm{CO}_{2}}$ is the temperature dependent Henry's constant for $\mathrm{CO}_{2}(\mathrm{~Pa} /$ ppm), and $\mathrm{C}_{\mathrm{CO}_{2}}^{t=i}$ is the $\mathrm{CO}_{2}$ concentration dissolved into the product $(\mathrm{mg} / \mathrm{kg})$. Assuming that $\mathrm{CO}_{2}$ and $\mathrm{O}_{2}$ dissolves mainly in the water phase, one can adjust the Henry's constant for $\mathrm{CO}_{2}$ (Carroll et al., 1991) and $\mathrm{O}_{2}$ (Prini and Crovetto, 1989) in water to the water content in the chicken fillets resulting in $41.9 \mathrm{~Pa} / \mathrm{ppm}$ for $\mathrm{CO}_{2}$ and $2263 \mathrm{~Pa} / \mathrm{ppm}$ for $\mathrm{O}_{2}$ at $2{ }^{\circ} \mathrm{C}$.

The $\mathrm{O}_{2}$ solubility in the product was measured using Equation (3).

$P_{\mathrm{O}_{2}}^{t=i}=H_{\mathrm{O}_{2, p}} \times \mathrm{C}_{\mathrm{O}_{2}}^{t=i}$

Where $P_{\mathrm{O}_{2}}^{t=i}$ is the partial pressure of $\mathrm{O}_{2}$ in the headspace ( $\mathrm{Pa}$ ), $\mathrm{H}_{\mathrm{O}_{2}}$ is the temperature dependent Henry's constant for $\mathrm{O}_{2}(\mathrm{~Pa} / \mathrm{ppm})$, and $\mathrm{C}_{\mathrm{O}_{2}}^{t=i}$ is the $\mathrm{O}_{2}$ concentration dissolved into the product (ppm).

\subsection{Statistical analysis}

All bacterial counts obtained from each sample were averaged and converted to $\log _{10} \mathrm{CFU} / \mathrm{g}$. All experiments were repeated on 3 separate occasions. A least significant difference analysis was performed using GENSTAT ver. 12.1 (VSN International Ltd, Hemel Hempstead, UK).

\section{Results}

On day 0 the mean Campylobacter (inoculated), TVC mesophile, TVC psychrophile, TEC, LAB and Pseudomonas counts were 4.4, 2.61, 3.1, 1.64, 1.58 and $2.4 \log _{10} \mathrm{CFU} / \mathrm{cm}^{2}$, respectively.

Campylobacter counts for all treatments were reduced during the 17 days of storage (Table 1 ). Although the decline was fastest in the control (air) and other gaseous combinations that included $\mathrm{O}_{2}$ (80:20\% $\mathrm{O}_{2}: \mathrm{N}_{2}$ and 40:30:30\% $\mathrm{CO}_{2}: \mathrm{O}_{2}: \mathrm{N}_{2}$ ) these differences were not statistically significant $(P>0.05)$ with the exception of $50: 50 \%$ $\mathrm{N}_{2}: \mathrm{CO}_{2}$ versus $80: 20 \% \mathrm{O}_{2}: \mathrm{N}_{2}$ (9 days), $50: 50 \% \mathrm{~N}_{2}: \mathrm{CO}_{2}$ versus $80: 20 \%$ $\mathrm{O}_{2}: \mathrm{N}_{2}$ and the control (11 days) and $70: 30 \% \mathrm{~N}_{2}: \mathrm{CO}_{2}$ versus the control after 17 days.

In contrast to Campylobacter, TVC mesophile counts increased throughout the 17 days storage (Table 2). After 4 days the counts obtained with $10: 90 \% \mathrm{~N}_{2}: \mathrm{CO}_{2}$ and $30: 70 \mathrm{~N}_{2}: \mathrm{CO}_{2}$ were significantly $(P>0.05)$ less than the control and the 80:20\% $\mathrm{O}_{2}: \mathrm{N}_{2}$ count. One day later the $50: 50 \% \mathrm{~N}_{2}: \mathrm{CO}_{2}$ treated fillets were also significantly lower than the control and by 7 days, all treatments with the exception of 90:10\% $\mathrm{N}_{2}: \mathrm{CO}_{2}$ and $80: 20 \% \quad \mathrm{O}_{2}: \mathrm{N}_{2}$ demonstrated significantly $(P<0.05)$ reduced growth. This pattern was maintained until 14 days when the latter was the only treatment that was statistically similar to the control. By 17 days there was an approximate $5 \log _{10} \mathrm{CFU} / \mathrm{cm}^{2}$ difference between the control and any of the MAP treatments that contained $50 \%$ or higher $\mathrm{CO}_{2}$.

A similar pattern was observed with the TVC psychrophile counts (Table 3 ). After 4 days, MAP treatments that contained $50 \%$ or higher $\mathrm{CO}_{2}$ showed significantly $(P<0.05)$ reduced growth as compared to the control. These were joined by $70: 30 \% \mathrm{~N}_{2}: \mathrm{CO}_{2}$ after 7 days and $90: 10 \% \mathrm{~N}_{2}: \mathrm{CO}_{2}$ after 14 days. Interestingly, the 40:30:30 $\mathrm{CO}_{2}: \mathrm{O}_{2}: \mathrm{N}_{2}$ combination showed significantly less growth as compared to the control after 7 days and by 17 days was approximately $4 \log _{10} \mathrm{CFU} / \mathrm{cm}^{2}$ lower. 
Table 1

Mean Campylobacter counts $\left(\log _{10} \mathrm{CFU} / \mathrm{cm}^{2}\right)$ on chicken fillets packed in different MAP gaseous combinations over the course of 17 days storage at $2{ }^{\circ} \mathrm{C}$.

\begin{tabular}{|c|c|c|c|c|c|c|c|c|c|c|}
\hline \multirow[t]{2}{*}{ Treatment/storage (days) } & \multicolumn{10}{|c|}{ Campylobacter counts $\left(\log _{10} \mathrm{CFU} / \mathrm{cm}^{2}\right)$} \\
\hline & 1 & S.E $E^{a}$ & 2 & S.E & 3 & S.E & 4 & S.E & 5 & S.E \\
\hline Control (air) & $4.25^{\mathrm{A} / \mathrm{AB}}$ & 0.29 & $4.28^{\mathrm{A} / \mathrm{A}}$ & 0.26 & $4.17^{\mathrm{A} / \mathrm{AB}}$ & 0.27 & $3.98^{\mathrm{A} / \mathrm{ABC}}$ & 0.30 & $3.88^{\mathrm{A} / \mathrm{BC}}$ & 0.24 \\
\hline $10: 90 \mathrm{~N}_{2}: \mathrm{CO}_{2}$ & $4.23^{\mathrm{A} / \mathrm{AB}}$ & 0.22 & $4.23^{\mathrm{A} / \mathrm{AB}}$ & 0.26 & $4.32^{\mathrm{A} / \mathrm{A}}$ & 0.28 & $4.09^{\mathrm{A} / \mathrm{AB}}$ & 0.19 & $4.08^{\mathrm{A} / \mathrm{AB}}$ & 0.21 \\
\hline $30: 70 \mathrm{~N}_{2}: \mathrm{CO}_{2}$ & $4.43^{\mathrm{A} / \mathrm{A}}$ & 0.32 & $4.27^{\mathrm{A} / \mathrm{AB}}$ & 0.22 & $4.30^{\mathrm{A} / \mathrm{AB}}$ & 0.29 & $4.20^{\mathrm{A} / \mathrm{AB}}$ & 0.29 & $4.20^{\mathrm{A} / \mathrm{AB}}$ & 0.27 \\
\hline $50: 50 \mathrm{~N}_{2}: \mathrm{CO}_{2}$ & $4.37^{\mathrm{A} / \mathrm{A}}$ & 0.26 & $4.19^{\mathrm{A} / \mathrm{AB}}$ & 0.21 & $4.12^{\mathrm{A} / \mathrm{AB}}$ & 0.10 & $4.15^{\mathrm{A} / \mathrm{AB}}$ & 0.12 & $4.23^{\mathrm{A} / \mathrm{AB}}$ & 0.28 \\
\hline $70: 30 \mathrm{~N}_{2}: \mathrm{CO}_{2}$ & $4.41^{\mathrm{A} / \mathrm{A}}$ & 0.21 & $4.13^{\mathrm{A} / \mathrm{AB}}$ & 0.31 & $4.26^{\mathrm{A} / \mathrm{ABC}}$ & 0.31 & $4.06^{\mathrm{A} / \mathrm{ABC}}$ & 0.21 & $4.12^{\mathrm{A} / \mathrm{ABC}}$ & 0.24 \\
\hline $90: 10 \mathrm{~N}_{2}: \mathrm{CO}_{2}$ & $4.33^{\mathrm{A} / \mathrm{A}}$ & 0.26 & $4.30^{\mathrm{A} / \mathrm{A}}$ & 0.33 & $4.22^{\mathrm{A} / \mathrm{AB}}$ & 0.26 & $4.05^{\mathrm{A} / \mathrm{AB}}$ & 0.26 & $3.98^{\mathrm{A} / \mathrm{AB}}$ & 0.31 \\
\hline $80: 20 \mathrm{O}_{2}: \mathrm{N}_{2}$ & $4.29^{\mathrm{A} / \mathrm{A}}$ & 0.31 & $4.02^{\mathrm{A} / \mathrm{AB}}$ & 0.29 & $4.07^{\mathrm{A} / \mathrm{AB}}$ & 0.32 & $3.90^{\mathrm{A} / \mathrm{B}}$ & 0.25 & $3.85^{\mathrm{A} / \mathrm{BC}}$ & 0.28 \\
\hline $40: 30: 30 \mathrm{CO}_{2}: \mathrm{O}_{2}: \mathrm{N}_{2}$ & $4.22^{\mathrm{A} / \mathrm{A}}$ & 0.18 & $4.14^{\mathrm{A} / \mathrm{AB}}$ & 0.19 & $4.24^{\mathrm{A} / \mathrm{A}}$ & 0.31 & $3.99^{\mathrm{A} / \mathrm{AB}}$ & 0.27 & $4.02^{\mathrm{A} / \mathrm{AB}}$ & 0.24 \\
\hline \multirow[t]{2}{*}{ Treatment/storage (days) } & \multicolumn{10}{|c|}{ Campylobacter counts $\left(\log _{10} \mathrm{CFU} / \mathrm{cm}^{2}\right)$} \\
\hline & 7 & S.E & 9 & S.E & 11 & S.E & 14 & S.E & 17 & S.E \\
\hline Control (air) & $3.72^{\mathrm{A} / \mathrm{CD}}$ & 0.32 & $3.39^{\mathrm{AB} / \mathrm{DE}}$ & 0.39 & $3.14^{\mathrm{A} / \mathrm{E}}$ & 0.53 & $3.18^{\mathrm{A} / \mathrm{E}}$ & 0.37 & $2.99^{\mathrm{A} / \mathrm{E}}$ & 0.55 \\
\hline $10: 90 \mathrm{~N}_{2}: \mathrm{CO}_{2}$ & $4.01^{\mathrm{A} / \mathrm{ABC}}$ & 0.27 & $4.06^{\mathrm{AB} / \mathrm{AB}}$ & 0.23 & $3.91^{\mathrm{AB} / \mathrm{BC}}$ & 0.22 & $3.90^{\mathrm{A} / \mathrm{BC}}$ & 0.25 & $3.65^{\mathrm{AB} / \mathrm{C}}$ & 0.25 \\
\hline $30: 70 \mathrm{~N}_{2}: \mathrm{CO}_{2}$ & $4.19^{\mathrm{A} / \mathrm{AB}}$ & 0.33 & $4.02^{\mathrm{AB} / \mathrm{BC}}$ & 0.29 & $3.68^{\mathrm{AB} / \mathrm{CD}}$ & 0.29 & $3.61^{\mathrm{A} / \mathrm{D}}$ & 0.27 & $3.59^{\mathrm{AB} / \mathrm{D}}$ & 0.21 \\
\hline $50: 50 \mathrm{~N}_{2}: \mathrm{CO}_{2}$ & $4.17^{\mathrm{A} / \mathrm{AB}}$ & 0.24 & $4.15^{\mathrm{B} / \mathrm{AB}}$ & 0.18 & $4.15^{\mathrm{B} / \mathrm{AB}}$ & 0.29 & $3.93^{\mathrm{A} / \mathrm{B}}$ & 0.34 & $3.88^{\mathrm{AB} / \mathrm{B}}$ & 0.31 \\
\hline $70: 30 \mathrm{~N}_{2}: \mathrm{CO}_{2}$ & $4.09^{\mathrm{A} / \mathrm{ABC}}$ & 0.27 & $3.88^{\mathrm{AB} / \mathrm{BC}}$ & 0.25 & $3.89^{\mathrm{AB} / \mathrm{BC}}$ & 0.30 & $3.83^{\mathrm{A} / \mathrm{C}}$ & 0.37 & $3.96^{\mathrm{B} / \mathrm{BC}}$ & 0.37 \\
\hline $90: 10 \mathrm{~N}_{2}: \mathrm{CO}_{2}$ & $3.95^{\mathrm{A} / \mathrm{AB}}$ & 0.29 & $4.01^{\mathrm{AB} / \mathrm{AB}}$ & 0.34 & $3.87^{\mathrm{AB} / \mathrm{B}}$ & 0.31 & $3.90^{\mathrm{A} / \mathrm{B}}$ & 0.28 & $3.85^{\mathrm{AB} / \mathrm{B}}$ & 0.38 \\
\hline $80: 20 \mathrm{O}_{2}: \mathrm{N}_{2}$ & $3.47^{\mathrm{A} / \mathrm{CD}}$ & 0.33 & $3.23^{\mathrm{A} / \mathrm{DE}}$ & 0.36 & $3.17^{\mathrm{A} / \mathrm{DE}}$ & 0.34 & $3.15^{\mathrm{A} / \mathrm{DE}}$ & 0.24 & $3.09^{\mathrm{AB} / \mathrm{E}}$ & 0.33 \\
\hline $40: 30: 30 \mathrm{CO}_{2}: \mathrm{O}_{2}: \mathrm{N}_{2}$ & $3.77^{\mathrm{A} / \mathrm{BC}}$ & 0.32 & $3.53^{\mathrm{AB} / \mathrm{CD}}$ & 0.22 & $3.27^{\mathrm{AB} / \mathrm{C}}$ & 0.32 & $3.18^{\mathrm{A} / \mathrm{C}}$ & 0.30 & $3.19^{\mathrm{AB} / \mathrm{C}}$ & 0.37 \\
\hline
\end{tabular}

a S.E. = standard error; $\mathrm{X} / \mathrm{Y}, \mathrm{X}=$ Comparisons were made between treatments for a sampling stage, $\mathrm{Y}=$ Comparisons made between days. The same letter indicates not statistically different at the $5 \%$ level $(P>0.05)$.

Table 2

Mean TVC mesophile counts $\left(\log _{10} \mathrm{CFU} / \mathrm{cm}^{2}\right)$ on chicken fillets packed in different MAP gaseous combinations over the course of 17 days storage at $2{ }^{\circ} \mathrm{C}$.

\begin{tabular}{|c|c|c|c|c|c|c|c|c|c|c|}
\hline \multirow[t]{2}{*}{ Treatment/storage (days) } & \multicolumn{10}{|c|}{ TVC mesophile counts $\left(\log _{10} \mathrm{CFU} / \mathrm{cm}^{2}\right)$} \\
\hline & 1 & S.E $\mathrm{E}^{\mathrm{a}}$ & 2 & S.E & 3 & S.E & 4 & S.E & 5 & S.E \\
\hline Control (air) & $2.82^{\mathrm{A} / \mathrm{A}}$ & 0.19 & $3.23^{\mathrm{A} / \mathrm{A}}$ & 0.06 & $4.07^{\mathrm{A} / \mathrm{AB}}$ & 0.34 & $4.82^{\mathrm{B} / \mathrm{B}}$ & 0.14 & $5.22^{\mathrm{CD} / \mathrm{B}}$ & 0.32 \\
\hline $10: 90 \mathrm{~N}_{2}: \mathrm{CO}_{2}$ & $2.33^{\mathrm{A} / \mathrm{A}}$ & 0.13 & $2.74^{\mathrm{A} / \mathrm{A}}$ & 0.22 & $2.97^{\mathrm{A} / \mathrm{A}}$ & 0.18 & $2.91^{\mathrm{A} / \mathrm{A}}$ & 0.23 & $3.15^{\mathrm{AB} / \mathrm{A}}$ & 0.20 \\
\hline $30: 70 \mathrm{~N}_{2}: \mathrm{CO}_{2}$ & $2.85^{\mathrm{A} / \mathrm{A}}$ & 0.46 & $2.73^{\mathrm{A} / \mathrm{A}}$ & 0.19 & $2.90^{\mathrm{A} / \mathrm{A}}$ & 0.13 & $2.95^{\mathrm{A} / \mathrm{A}}$ & 0.12 & $2.87^{\mathrm{A} / \mathrm{A}}$ & 0.35 \\
\hline $50: 50 \mathrm{~N}_{2}: \mathrm{CO}_{2}$ & $2.54^{\mathrm{A} / \mathrm{A}}$ & 0.10 & $2.63^{\mathrm{A} / \mathrm{A}}$ & 0.16 & $2.91^{\mathrm{A} / \mathrm{A}}$ & 0.10 & $3.21^{\mathrm{AB} / \mathrm{AB}}$ & 0.06 & $3.13^{\mathrm{AB} / \mathrm{AB}}$ & 0.27 \\
\hline $70: 30 \mathrm{~N}_{2}: \mathrm{CO}_{2}$ & $3.17^{\mathrm{A} / \mathrm{AB}}$ & 0.29 & $2.92^{\mathrm{A} / \mathrm{AB}}$ & 0.32 & $2.71^{\mathrm{A} / \mathrm{A}}$ & 0.17 & $3.72^{\mathrm{AB} / \mathrm{AB}}$ & 0.21 & $3.65^{\mathrm{ABC} / \mathrm{AB}}$ & 0.45 \\
\hline $90: 10 \mathrm{~N}_{2}: \mathrm{CO}_{2}$ & $3.09^{\mathrm{A} / \mathrm{A}}$ & 0.15 & $3.18^{\mathrm{A} / \mathrm{A}}$ & 0.28 & $3.40^{\mathrm{A} / \mathrm{AB}}$ & 0.33 & $4.50^{\mathrm{AB} / \mathrm{BC}}$ & 0.08 & $5.32^{\mathrm{D} / \mathrm{CD}}$ & 0.42 \\
\hline $80: 20 \mathrm{O}_{2}: \mathrm{N}_{2}$ & $2.73^{\mathrm{A} / \mathrm{A}}$ & 0.15 & $3.83^{\mathrm{A} / \mathrm{AB}}$ & 0.45 & $4.00^{\mathrm{A} / \mathrm{AB}}$ & 0.03 & $4.75^{\mathrm{B} / \mathrm{BC}}$ & 0.12 & $5.78^{\mathrm{D} / \mathrm{CD}}$ & 0.75 \\
\hline $40: 30: 30 \mathrm{CO}_{2}: \mathrm{O}_{2}: \mathrm{N}_{2}$ & $2.64^{\mathrm{A} / \mathrm{A}}$ & 0.20 & $2.71^{\mathrm{A} / \mathrm{A}}$ & 0.14 & $2.99^{\mathrm{A} / \mathrm{A}}$ & 0.28 & $3.25^{\mathrm{AB} / \mathrm{A}}$ & 0.20 & $4.65 \mathrm{~B}^{\mathrm{CD} / \mathrm{B}}$ & 0.42 \\
\hline \multirow[t]{2}{*}{ Treatment/storage (days) } & \multicolumn{10}{|c|}{ TVC mesophile counts $\left(\log _{10} \mathrm{CFU} / \mathrm{cm}^{2}\right)$} \\
\hline & 7 & S.E & 9 & S.E & 11 & S.E & 14 & S.E & 17 & S.E \\
\hline Control (air) & $6.77^{\mathrm{C} / \mathrm{C}}$ & 0.07 & $9.23^{\mathrm{C} / \mathrm{D}}$ & 0.07 & $10.70^{\mathrm{C} / \mathrm{E}}$ & 0.66 & $10.84^{\mathrm{C} / \mathrm{E}}$ & 0.38 & $10.26^{\mathrm{E} / \mathrm{DE}}$ & 0.25 \\
\hline $10: 90 \mathrm{~N}_{2}: \mathrm{CO}_{2}$ & $4.84^{\mathrm{AB} / \mathrm{B}}$ & 0.43 & $6.23^{\mathrm{AB} / \mathrm{C}}$ & 0.30 & $6.25^{\mathrm{AB} / \mathrm{C}}$ & 0.34 & $6.01^{\mathrm{A} / \mathrm{BC}}$ & 0.29 & $5.41^{\mathrm{AB} / \mathrm{BC}}$ & 0.12 \\
\hline $30: 70 \mathrm{~N}_{2}: \mathrm{CO}_{2}$ & $3.61^{\mathrm{A} / \mathrm{A}}$ & 0.58 & $5.65^{\mathrm{A} / \mathrm{B}}$ & 0.50 & $5.36^{\mathrm{A} / \mathrm{B}}$ & 0.55 & $5.88^{\mathrm{A} / \mathrm{B}}$ & 0.37 & $5.15^{\mathrm{A} / \mathrm{B}}$ & 0.25 \\
\hline $50: 50 \mathrm{~N}_{2}: \mathrm{CO}_{2}$ & $4.27^{\mathrm{A} / \mathrm{BC}}$ & 0.60 & $5.40^{\mathrm{A} / \mathrm{CD}}$ & 0.55 & $6.29^{\mathrm{AB} / \mathrm{D}}$ & 0.40 & $6.20^{\mathrm{A} / \mathrm{D}}$ & 0.11 & $5.76^{\mathrm{AB} / \mathrm{D}}$ & 0.69 \\
\hline $70: 30 \mathrm{~N}_{2}: \mathrm{CO}_{2}$ & $4.17^{\mathrm{A} / \mathrm{B}}$ & 0.39 & $5.48^{\mathrm{A} / \mathrm{C}}$ & 0.17 & $6.98^{\mathrm{AB} / \mathrm{D}}$ & 0.42 & $7.11^{\mathrm{AB} / \mathrm{D}}$ & 0.13 & $6.95^{\mathrm{BC} / \mathrm{D}}$ & 0.37 \\
\hline $90: 10 \mathrm{~N}_{2}: \mathrm{CO}_{2}$ & $5.99^{\mathrm{BC} / \mathrm{D}}$ & 0.52 & $7.67^{\mathrm{BC} / \mathrm{E}}$ & 0.55 & $7.85^{\mathrm{BC} / \mathrm{E}}$ & 0.37 & $8.39^{\mathrm{B} / \mathrm{E}}$ & 0.44 & $7.76^{\mathrm{CD} / \mathrm{E}}$ & 0.13 \\
\hline $80: 20 \mathrm{O}_{2}: \mathrm{N}_{2}$ & $6.64^{\mathrm{C} / \mathrm{D}}$ & 0.68 & $8.04^{\mathrm{C} / \mathrm{E}}$ & 0.59 & $9.41^{\mathrm{C} / \mathrm{F}}$ & 0.19 & $10.79^{\mathrm{C} / \mathrm{G}}$ & 0.27 & $9.20^{\mathrm{DE} / \mathrm{EF}}$ & 0.85 \\
\hline $40: 30: 30 \mathrm{CO}_{2}: \mathrm{O}_{2}: \mathrm{N}_{2}$ & $4.63^{\mathrm{AB} / \mathrm{B}}$ & 0.65 & $5.45^{\mathrm{A} / \mathrm{BC}}$ & 0.49 & $6.20^{\mathrm{A} / \mathrm{C}}$ & 0.17 & $6.53^{\mathrm{A} / \mathrm{C}}$ & 0.21 & $6.46^{\mathrm{ABC} / \mathrm{C}}$ & 0.41 \\
\hline
\end{tabular}

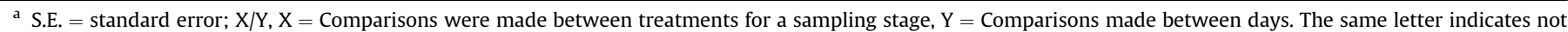
statistically different at the $5 \%$ level $(P>0.05)$.

With TEC the effect of $40: 30: 30 \% \mathrm{CO}_{2}: \mathrm{O}_{2}: \mathrm{N}_{2}$ was observed more quickly as fillets packed in this MAP treatment showed significantly $(P<0.05)$ reduced growth after 5 days and $3 \log _{10}$ cfu per $\mathrm{cm}^{2}$ less of growth after 17 days (Table 4). As with TVC, the most effective treatments at inhibiting TEC were those that contained $\mathrm{CO}_{2}$ with $\mathrm{N}_{2}$ filler. Significant growth inhibition was obtained after 3 days with $70 \% \mathrm{CO}_{2}$ and 7 days with concentrations of $30 \%$ or higher.

Data for the spoilage organisms, lactic acid bacteria (LAB) and Pseudomonas are shown in Tables 5 and 6, respectively. Overall treatments with $50 \%$ or more $\mathrm{CO}_{2}$ inhibited the growth of $\mathrm{LAB}$ but the effect was not as clear cut as was observed with TVC and TEC and after 17 days there was no significant difference between the control and 50:50\% $\mathrm{N}_{2}: \mathrm{CO}_{2}$ counts. Furthermore, most samples from $70: 30 \% \mathrm{~N}_{2}: \mathrm{CO}_{2}, 90: 10 \% \mathrm{~N}_{2}: \mathrm{CO}_{2}$ and $80: 20 \% \mathrm{O}_{2}: \mathrm{N}_{2}$ packs showed LAB counts that were similar or higher than the control counts. After 5 days, all treatments, with the exception of $90: 10 \%$ $\mathrm{N}_{2}: \mathrm{CO}_{2}$ and $80: 20 \% \mathrm{O}_{2}: \mathrm{N}_{2}$ showed reduced Pseudomonas growth
(Table 6). After 9 days only the latter was statistically similar to the control counts. By the end of the storage period, MAP treatments with $30 \% \mathrm{CO}_{2}$ or higher with $\mathrm{N}_{2}$ making up the remaining gas were approximately 4.5-6.0 $\log _{10} \mathrm{CFU} / \mathrm{cm}^{2}$ lower than the control counts. Overall these treatments extended the shelf-life of fresh chicken fillets from approximately 7 days to in excess of 17 days.

While the presence of $\mathrm{CO}_{2}$ inhibited TVC, TEC, LAB and Pseudomonas growth, for the majority of samples, this effect was not statistically significant $(P>0.05)$ until after 5 days of storage after which time the concentration of $\mathrm{CO}_{2}(\mathrm{ppm})$ in the chicken fillets was less than $250 \mathrm{ppm}$ in control, 80:20\% $\mathrm{O}_{2}: \mathrm{N}_{2}$ and $90: 10 \% \mathrm{~N}_{2}: \mathrm{CO}_{2}$ packs, $500-1000$ ppm in 70:30\% $\mathrm{N}_{2}: \mathrm{CO}_{2}, 40: 30: 30 \% \mathrm{CO}_{2}: \mathrm{O}_{2}: \mathrm{N}_{2}$ and $50: 50 \% \mathrm{~N}_{2}: \mathrm{CO}_{2}$ packs, $1000-1500$ ppm for $30: 70 \% \mathrm{~N}_{2}: \mathrm{CO}_{2}$ and up to $2000 \mathrm{ppm}$ in $10: 90 \% \mathrm{~N}_{2}: \mathrm{CO}_{2}$ packs (Fig. 1). In contrast the concentration of $\mathrm{O}_{2}$ dissolved in the fillets decreased from 34 to $0 \mathrm{ppm}$ over the 17 day duration of the experiment in $80: 20 \% \mathrm{O}_{2}: \mathrm{N}_{2}$ packs; from 9 to $0 \mathrm{ppm}$ in the control samples over 8 days and from 
Table 3

Mean TVC psychrophilic counts $\left(\log _{10} \mathrm{CFU} / \mathrm{cm}^{2}\right)$ on chicken fillets packed in different MAP gaseous combinations over the course of 17 days storage at $2{ }^{\circ} \mathrm{C}$.

\begin{tabular}{|c|c|c|c|c|c|c|c|c|c|c|}
\hline \multirow[t]{2}{*}{ Treatment/storage (days) } & \multicolumn{10}{|c|}{ TVC psychrophile counts $\left(\log _{10} \mathrm{CFU} / \mathrm{cm}^{2}\right)$} \\
\hline & 1 & S.E $E^{a}$ & 2 & S.E & 3 & S.E & 4 & S.E & 5 & S.E \\
\hline Control (air) & $2.99^{\mathrm{A} / \mathrm{A}}$ & 0.18 & $3.31^{\mathrm{AB} / \mathrm{A}}$ & 0.14 & $3.89^{\mathrm{A} / \mathrm{AB}}$ & 0.47 & $4.72^{\mathrm{C} / \mathrm{B}}$ & 0.13 & $4.75^{\mathrm{BC} / \mathrm{B}}$ & 0.62 \\
\hline $10: 90 \mathrm{~N}_{2}: \mathrm{CO}_{2}$ & $2.45^{\mathrm{A} / \mathrm{A}}$ & 0.26 & $2.83^{\mathrm{AB} / \mathrm{A}}$ & 0.20 & $2.49^{\mathrm{A} / \mathrm{A}}$ & 0.47 & $2.96^{\mathrm{A} / \mathrm{A}}$ & 0.24 & $2.89^{\mathrm{A} / \mathrm{A}}$ & 0.39 \\
\hline $30: 70 \mathrm{~N}_{2}: \mathrm{CO}_{2}$ & $3.11^{\mathrm{A} / \mathrm{AB}}$ & 0.37 & $2.37^{\mathrm{A} / \mathrm{A}}$ & 0.33 & $2.72^{\mathrm{A} / \mathrm{AB}}$ & 0.21 & $3.00^{\mathrm{A} / \mathrm{AB}}$ & 0.10 & $3.02^{\mathrm{A} / \mathrm{AB}}$ & 0.30 \\
\hline $50: 50 \mathrm{~N}_{2}: \mathrm{CO}_{2}$ & $2.66^{\mathrm{A} / \mathrm{A}}$ & 0.18 & $2.64^{\mathrm{AB} / \mathrm{A}}$ & 0.14 & $2.73^{\mathrm{A} / \mathrm{AB}}$ & 0.14 & $3.03^{\mathrm{AB} / \mathrm{AB}}$ & 0.08 & $3.11^{\mathrm{A} / \mathrm{AB}}$ & 0.31 \\
\hline $70: 30 \mathrm{~N}_{2}: \mathrm{CO}_{2}$ & $3.12^{\mathrm{A} / \mathrm{AB}}$ & 0.37 & $2.92^{\mathrm{AB} / \mathrm{A}}$ & 0.31 & $2.80^{\mathrm{A} / \mathrm{A}}$ & 0.14 & $3.66^{\mathrm{ABC} / \mathrm{AB}}$ & 0.24 & $3.63^{\mathrm{AB} / \mathrm{AB}}$ & 0.42 \\
\hline $90: 10 \mathrm{~N}_{2}: \mathrm{CO}_{2}$ & $3.04^{\mathrm{A} / \mathrm{A}}$ & 0.14 & $3.05^{\mathrm{AB} / \mathrm{A}}$ & 0.35 & $3.50^{\mathrm{A} / \mathrm{AB}}$ & 0.31 & $4.50^{\mathrm{BC} / \mathrm{BC}}$ & 0.05 & $5.08^{\mathrm{BC} / \mathrm{CD}}$ & 0.25 \\
\hline $80: 20 \mathrm{O}_{2}: \mathrm{N}_{2}$ & $2.85^{\mathrm{A} / \mathrm{A}}$ & 0.06 & $3.90^{\mathrm{B} / \mathrm{AB}}$ & 0.43 & $3.95^{\mathrm{A} / \mathrm{AB}}$ & 0.03 & $4.59^{\mathrm{C} / \mathrm{ABC}}$ & 0.08 & $5.51^{\mathrm{C} / \mathrm{BC}}$ & 0.62 \\
\hline $40: 30: 30 \mathrm{CO}_{2}: \mathrm{O}_{2}: \mathrm{N}_{2}$ & $2.56^{\mathrm{A} / \mathrm{AB}}$ & 0.14 & $2.27^{\mathrm{A} / \mathrm{A}}$ & 0.35 & $2.81^{\mathrm{A} / \mathrm{AB}}$ & 0.30 & $3.25^{\mathrm{ABC} / \mathrm{AB}}$ & 0.15 & $3.69^{\mathrm{AB} / \mathrm{B}}$ & 0.61 \\
\hline \multirow[t]{2}{*}{ Treatment/storage (days) } & \multicolumn{10}{|c|}{ TVC psychrophile counts $\left(\log _{10} \mathrm{CFU} / \mathrm{cm}^{2}\right)$} \\
\hline & 7 & S.E & 9 & S.E & 11 & S.E & 14 & S.E & 17 & S.E \\
\hline Control (air) & $6.83^{\mathrm{D} / \mathrm{C}}$ & 0.15 & $8.69^{C / D}$ & 0.27 & $8.76^{\mathrm{C} / \mathrm{D}}$ & 0.93 & $11.15^{\mathrm{C} / \mathrm{E}}$ & 0.44 & $11.04^{\mathrm{C} / \mathrm{E}}$ & 0.07 \\
\hline $10: 90 \mathrm{~N}_{2}: \mathrm{CO}_{2}$ & $5.15^{\mathrm{ABC} / \mathrm{B}}$ & 0.31 & $6.30^{\mathrm{AB} / \mathrm{B}}$ & 0.34 & $5.25^{\mathrm{A} / \mathrm{B}}$ & 0.29 & $6.12^{\mathrm{A} / \mathrm{B}}$ & 0.49 & $6.14^{\mathrm{A} / \mathrm{B}}$ & 0.30 \\
\hline $30: 70 \mathrm{~N}_{2}: \mathrm{CO}_{2}$ & $3.75^{\mathrm{A} / \mathrm{B}}$ & 0.65 & $5.57^{\mathrm{A} / \mathrm{C}}$ & 0.49 & $5.12^{\mathrm{A} / \mathrm{C}}$ & 0.52 & $5.61^{\mathrm{A} / \mathrm{C}}$ & 0.08 & $5.83^{\mathrm{A} / \mathrm{C}}$ & 0.25 \\
\hline $50: 50 \mathrm{~N}_{2}: \mathrm{CO}_{2}$ & $3.92^{\mathrm{A} / \mathrm{BC}}$ & 0.40 & $5.09^{\mathrm{A} / \mathrm{CD}}$ & 0.40 & $6.28^{\mathrm{AB} / \mathrm{DE}}$ & 0.55 & $6.33^{\mathrm{AB} / \mathrm{E}}$ & 0.34 & $6.73^{\mathrm{A} / \mathrm{E}}$ & 0.12 \\
\hline $70: 30 \mathrm{~N}_{2}: \mathrm{CO}_{2}$ & $4.24^{\mathrm{AB} / \mathrm{B}}$ & 0.34 & $5.56^{\mathrm{A} / \mathrm{C}}$ & 0.15 & $7.13^{\mathrm{B} / \mathrm{D}}$ & 0.30 & $6.85^{\mathrm{AB} / \mathrm{D}}$ & 0.14 & $7.22^{\mathrm{AB} / \mathrm{D}}$ & 0.17 \\
\hline $90: 10 \mathrm{~N}_{2}: \mathrm{CO}_{2}$ & $5.71^{\mathrm{BCD} / \mathrm{D}}$ & 0.17 & $7.74^{\mathrm{BC} / \mathrm{E}}$ & 0.57 & $7.56^{\mathrm{BC} / \mathrm{E}}$ & 0.25 & $7.64^{\mathrm{B} / \mathrm{E}}$ & 0.16 & $8.49^{\mathrm{B} / \mathrm{E}}$ & 0.36 \\
\hline $80: 20 \mathrm{O}_{2}: \mathrm{N}_{2}$ & $6.16^{\mathrm{CD} / \mathrm{C}}$ & 0.35 & $8.01^{C / D}$ & 0.36 & $8.72^{\mathrm{C} / \mathrm{D}}$ & 0.25 & $10.17^{\mathrm{C} / \mathrm{E}}$ & 0.32 & $10.79^{\mathrm{C} / \mathrm{E}}$ & 0.33 \\
\hline $40: 30: 30 \mathrm{CO}_{2}: \mathrm{O}_{2}: \mathrm{N}_{2}$ & $5.04^{\mathrm{ABC} / \mathrm{C}}$ & 0.95 & $5.57^{\mathrm{A} / \mathrm{CD}}$ & 0.52 & $6.24^{\mathrm{AB} / \mathrm{CDE}}$ & 0.30 & $6.47^{\mathrm{AB} / \mathrm{DE}}$ & 0.18 & $7.16^{\mathrm{AB} / \mathrm{E}}$ & 0.12 \\
\hline
\end{tabular}

a S.E. = standard error; $\mathrm{X} / \mathrm{Y}, \mathrm{X}=$ Comparisons were made between treatments for a sampling stage, $\mathrm{Y}=$ Comparisons made between days. The same letter indicates not statistically different at the $5 \%$ level $(P>0.05)$.

Table 4

Mean total Enterobacteriaceae counts (TEC, $\log _{10} \mathrm{CFU} / \mathrm{cm}^{2}$ ) on chicken fillets packed in different MAP gaseous combinations over the course of 17 days storage at $2{ }^{\circ} \mathrm{C}$.

\begin{tabular}{|c|c|c|c|c|c|c|c|c|c|c|}
\hline \multirow[t]{2}{*}{ Treatment/storage (days) } & \multicolumn{10}{|c|}{ Total Enterobacteriaceae counts $\left(\log _{10} \mathrm{CFU} / \mathrm{cm}^{2}\right)$} \\
\hline & 1 & S.E $E^{a}$ & 2 & S.E & 3 & S.E & 4 & S.E & 5 & S.E \\
\hline Control (air) & $1.83^{\mathrm{A} / \mathrm{A}}$ & 0.29 & $2.21^{\mathrm{A} / \mathrm{A}}$ & 0.12 & $3.58^{\mathrm{B} / \mathrm{B}}$ & 0.37 & $2.67^{\mathrm{BC} / \mathrm{AB}}$ & 0.41 & $3.88^{\mathrm{CD} / \mathrm{BC}}$ & 0.14 \\
\hline $10: 90 \mathrm{~N}_{2}: \mathrm{CO}_{2}$ & $1.69^{\mathrm{A} / \mathrm{A}}$ & 0.17 & $2.20^{\mathrm{A} / \mathrm{AB}}$ & 0.12 & $2.26^{\mathrm{AB} / \mathrm{AB}}$ & 0.48 & $1.25^{\mathrm{A} / \mathrm{A}}$ & 0.54 & $1.26^{\mathrm{A} / \mathrm{A}}$ & 0.24 \\
\hline $30: 70 \mathrm{~N}_{2}: \mathrm{CO}_{2}$ & $2.08^{\mathrm{A} / \mathrm{ABC}}$ & 0.43 & $1.53^{\mathrm{A} / \mathrm{A}}$ & 0.06 & $2.43^{\mathrm{AB} / \mathrm{ABC}}$ & 0.23 & $1.71^{\mathrm{ABC} / \mathrm{AB}}$ & 0.26 & $2.10^{\mathrm{AB} / \mathrm{ABC}}$ & 0.32 \\
\hline $50: 50 \mathrm{~N}_{2}: \mathrm{CO}_{2}$ & $1.50^{\mathrm{A} / \mathrm{A}}$ & 0.19 & $1.89^{\mathrm{A} / \mathrm{AB}}$ & 0.19 & $2.45^{\mathrm{AB} / \mathrm{ABC}}$ & 0.17 & $1.62^{\mathrm{ABC} / \mathrm{A}}$ & 0.59 & $2.24^{\mathrm{AB} / \mathrm{AB}}$ & 0.12 \\
\hline $70: 30 \mathrm{~N}_{2}: \mathrm{CO}_{2}$ & $2.05^{\mathrm{A} / \mathrm{A}}$ & 0.37 & $2.21^{\mathrm{A} / \mathrm{A}}$ & 0.07 & $2.19^{\mathrm{A} / \mathrm{A}}$ & 0.16 & $2.02^{\mathrm{ABC} / \mathrm{A}}$ & 0.39 & $2.78^{\mathrm{BC} / \mathrm{AB}}$ & 0.22 \\
\hline $90: 10 \mathrm{~N}_{2}: \mathrm{CO}_{2}$ & $1.67^{\mathrm{A} / \mathrm{A}}$ & 0.23 & $2.06^{\mathrm{A} / \mathrm{AB}}$ & 0.13 & $3.16^{\mathrm{AB} / \mathrm{BCD}}$ & 0.20 & $2.96^{\mathrm{C} / \mathrm{BC}}$ & 0.68 & $4.15^{\mathrm{D} / \mathrm{CD}}$ & 0.23 \\
\hline $80: 20 \mathrm{O}_{2}: \mathrm{N}_{2}$ & $1.47^{\mathrm{A} / \mathrm{A}}$ & 0.51 & $2.27^{\mathrm{A} / \mathrm{AB}}$ & 0.19 & $3.11^{\mathrm{AB} / \mathrm{BC}}$ & 0.16 & $2.01^{\mathrm{ABC} / \mathrm{AB}}$ & 0.58 & $3.85^{\mathrm{CD} / \mathrm{CD}}$ & 0.18 \\
\hline $40: 30: 30 \mathrm{CO}_{2}: \mathrm{O}_{2}: \mathrm{N}_{2}$ & $1.53^{\mathrm{A} / \mathrm{AB}}$ & 0.15 & $1.95^{\mathrm{A} / \mathrm{AB}}$ & 0.05 & $2.73^{\mathrm{AB} / \mathrm{BC}}$ & 0.17 & $1.39^{\mathrm{AB} / \mathrm{A}}$ & 0.48 & $2.22^{\mathrm{AB} / \mathrm{ABC}}$ & 0.06 \\
\hline \multirow[t]{2}{*}{ Treatment/storage (days) } & \multicolumn{10}{|c|}{ Total Enterobacteriaceae counts $\left(\log _{10} \mathrm{CFU} / \mathrm{cm}^{2}\right)$} \\
\hline & 7 & S.E & 9 & S.E & 11 & S.E & 14 & S.E & 17 & S.E \\
\hline Control (air) & $\overline{5.07^{\mathrm{C} / \mathrm{CD}}}$ & 0.16 & $5.92^{\mathrm{C} / \mathrm{DE}}$ & 0.54 & $6.52^{\mathrm{D} / \mathrm{E}}$ & 0.74 & $7.82^{\mathrm{D} / \mathrm{F}}$ & 0.60 & $8.45^{\mathrm{D} / \mathrm{F}}$ & 0.45 \\
\hline $10: 90 \mathrm{~N}_{2}: \mathrm{CO}_{2}$ & $3.26^{\mathrm{AB} / \mathrm{B}}$ & 0.46 & $3.10^{\mathrm{AB} / \mathrm{B}}$ & 0.40 & $3.42^{\mathrm{AB} / \mathrm{B}}$ & 0.30 & $3.47^{\mathrm{AB} / \mathrm{B}}$ & 0.59 & $5.17^{\mathrm{AB} / \mathrm{C}}$ & 0.32 \\
\hline $30: 70 \mathrm{~N}_{2}: \mathrm{CO}_{2}$ & $3.00^{\mathrm{AB} / \mathrm{CD}}$ & 0.29 & $4.04^{\mathrm{B} / \mathrm{DE}}$ & 0.28 & $2.87^{\mathrm{A} / \mathrm{BCD}}$ & 0.28 & $2.36^{\mathrm{A} / \mathrm{ABC}}$ & 0.40 & $4.31^{\mathrm{A} / \mathrm{E}}$ & 0.36 \\
\hline $50: 50 \mathrm{~N}_{2}: \mathrm{CO}_{2}$ & $3.05^{\mathrm{AB} / \mathrm{BCD}}$ & 0.45 & $3.08^{\mathrm{AB} / \mathrm{BCD}}$ & 0.27 & $3.67^{\mathrm{AB} / \mathrm{CDE}}$ & 0.28 & $4.08^{\mathrm{B} / \mathrm{DE}}$ & 0.16 & $4.81^{\mathrm{A} / \mathrm{E}}$ & 0.19 \\
\hline $70: 30 \mathrm{~N}_{2}: \mathrm{CO}_{2}$ & $3.10^{\mathrm{AB} / \mathrm{ABC}}$ & 0.32 & $3.53^{\mathrm{AB} / \mathrm{BC}}$ & 0.33 & $4.09^{B / C}$ & 0.65 & $5.55^{\mathrm{CD} / \mathrm{D}}$ & 0.11 & $6.21^{\mathrm{BC} / \mathrm{D}}$ & 0.21 \\
\hline $90: 10 \mathrm{~N}_{2}: \mathrm{CO}_{2}$ & $4.27^{\mathrm{BC} / \mathrm{D}}$ & 0.13 & $6.14^{\mathrm{C} / \mathrm{E}}$ & 0.14 & $6.61^{\mathrm{D} / \mathrm{EF}}$ & 0.24 & $7.31^{\mathrm{D} / \mathrm{EF}}$ & 0.20 & $7.85^{\mathrm{D} / \mathrm{F}}$ & 0.38 \\
\hline $80: 20 \mathrm{O}_{2}: \mathrm{N}_{2}$ & $4.37^{\mathrm{BC} / \mathrm{CD}}$ & 0.16 & $5.71^{\mathrm{C} / \mathrm{E}}$ & 0.30 & $5.09^{\mathrm{C} / \mathrm{DE}}$ & 0.34 & $5.67^{\mathrm{CD} / \mathrm{E}}$ & 0.62 & $7.43^{\mathrm{CD} / \mathrm{F}}$ & 0.22 \\
\hline $40: 30: 30 \mathrm{CO}_{2}: \mathrm{O}_{2}: \mathrm{N}_{2}$ & $2.70^{\mathrm{A} / \mathrm{BC}}$ & 0.32 & $2.54^{\mathrm{A} / \mathrm{ABC}}$ & 0.18 & $3.32^{\mathrm{AB} / \mathrm{C}}$ & 0.24 & $3.23^{\mathrm{AB} / \mathrm{C}}$ & 0.22 & $5.36^{\mathrm{AB} / \mathrm{D}}$ & 0.09 \\
\hline
\end{tabular}

a S.E. = standard error; $\mathrm{X} / \mathrm{Y}, \mathrm{X}=$ Comparisons were made between treatments for a sampling stage, $\mathrm{Y}=$ Comparisons made between days. The same letter indicates not statistically different at the $5 \%$ level $(P>0.05)$

$0.4-0.5 \mathrm{ppm}$ to 0 ppm over $1.7-2.8$ days in $10: 90 \% 30: 70 \% 50: 50 \%$ $70: 30 \%$ and $90: 10 \% \mathrm{~N}_{2}: \mathrm{CO}_{2}$ packs (Fig. 2). Interestingly the dissolved $\mathrm{O}_{2}$ concentration in $40: 30: 30 \% \mathrm{CO}_{2}: \mathrm{O}_{2}: \mathrm{N}_{2}$ packed chicken fillets remained at $11 \mathrm{ppm}$ throughout the experiment.

\section{Discussion}

Campylobacter declined more quickly in the presence of $\mathrm{O}_{2}$. Although Campylobacter respond to atmospheric oxygen exposure using an antioxidant defence system composed of superoxide dismutase, catalase or glutathione peroxidise activity (Storz and Imlay, 1999), which may result in long term aerobic adaptation (Jones et al., 1993; Harvey and Leach, 1998; Klancnik et al., 2009), our results suggest oxidative stress is still detrimental for the survival of at least a sub-population of cells. The decrease in Campylobacter levels observed in the $80: 20 \% \mathrm{O}_{2}: \mathrm{N}_{2}$ samples after 17 days of 1.26 $\log _{10}$ was similar to the $1.2 \log _{10}$ reduction reported by Rajkovic et al. (2010) but less than the 2.2 to $3.1 \log _{10}$ achieved by Boysen et al. (2007) using 70:30\% $\mathrm{O}_{2}: \mathrm{CO}_{2}$. In direct contrast to the effect of oxygen, $\mathrm{CO}_{2}$ in the MAP mixture apparently assisted the survival of Campylobacter, an effect that has also been previously reported (Boysen et al., 2007). This may be attributed to the inhibition of other organisms in gaseous mixtures containing $\mathrm{CO}_{2}$ as under normal atmospheric conditions Campylobacter are poor competitors (Huat et al., 2010).

$\mathrm{CO}_{2}$ inhibited the growth of TVC, TEC, LAB and Pseudomonas but only at concentrations of 50-90\% where a shelf-life in excess of 17 days at $2{ }^{\circ} \mathrm{C}$ was obtained. Reduced bacterial growth in $\mathrm{CO}_{2}$ packs is well documented (Gill et al., 1990) as is the concentration dependence of this effect (Patsias et al., 2006b). Indeed, Stiles (1991a,b), previously reported that a minimum $\mathrm{CO}_{2}$ concentration of $20-30 \%$ is required before an inhibitory effect is observed which is reasonably consistent with our observations. Based on a TVC mesophile count of $7 \log _{10} \mathrm{CFU} \mathrm{cm} \mathrm{cm}^{-2}$ as an indication of the end of shelf-life (ICMSF, 1986), the shelf-life of our fillets packed in air was 7 days which was extended to 11 days with $70: 30 \% \mathrm{~N}_{2}: \mathrm{CO}_{2}$ and in 
Table 5

Mean lactic acid bacteria (LAB) counts $\left(\log _{10} \mathrm{CFU} / \mathrm{cm}^{2}\right)$ on chicken fillets packed in different MAP gaseous combinations over the course of 17 days storage at $2{ }^{\circ} \mathrm{C}$.

\begin{tabular}{|c|c|c|c|c|c|c|c|c|c|c|}
\hline \multirow[t]{2}{*}{ Treatment/storage (days) } & \multicolumn{10}{|c|}{ Lactic acid bacteria (LAB) counts $\left(\log _{10} \mathrm{CFU} / \mathrm{cm}^{2}\right)$} \\
\hline & 1 & S.E $E^{a}$ & 2 & S.E & 3 & S.E & 4 & S.E & 5 & S.E \\
\hline Control & $1.68^{\mathrm{AB} / \mathrm{A}}$ & 0.56 & $1.94^{\mathrm{AB} / \mathrm{AB}}$ & 0.10 & $2.23^{\mathrm{BC} / \mathrm{BC}}$ & 0.26 & $2.65^{\mathrm{CD} / \mathrm{CD}}$ & 0.13 & $2.85^{\mathrm{BC} / \mathrm{D}}$ & 0.18 \\
\hline $10: 90 \mathrm{~N}_{2}: \mathrm{CO}_{2}$ & $1.69^{\mathrm{AB} / \mathrm{A}}$ & 0.16 & $2.00^{\mathrm{AB} / \mathrm{AB}}$ & 0.23 & $2.07^{\mathrm{ABC} / \mathrm{AB}}$ & 0.26 & $1.79^{\mathrm{A} / \mathrm{AB}}$ & 0.14 & $2.17^{\mathrm{A} / \mathrm{B}}$ & 0.26 \\
\hline $30: 70 \mathrm{~N}_{2}: \mathrm{CO}_{2}$ & $1.88^{\mathrm{ABCD} / \mathrm{ABC}}$ & 0.31 & $1.60^{\mathrm{A} / \mathrm{A}}$ & 0.37 & $1.85^{\mathrm{AB} / \mathrm{AB}}$ & 0.17 & $2.09^{\mathrm{AB} / \mathrm{BC}}$ & 0.08 & $2.29^{\mathrm{A} / \mathrm{CD}}$ & 0.19 \\
\hline $50: 50 \mathrm{~N}_{2}: \mathrm{CO}_{2}$ & $1.53^{\mathrm{A} / \mathrm{A}}$ & 0.27 & $1.99^{\mathrm{AB} / \mathrm{BC}}$ & 0.12 & $1.76^{\mathrm{A} / \mathrm{AB}}$ & 0.13 & $2.24^{\mathrm{BC} / \mathrm{C}}$ & 0.12 & $2.21^{\mathrm{A} / \mathrm{C}}$ & 0.24 \\
\hline $70: 30 \mathrm{~N}_{2}: \mathrm{CO}_{2}$ & $2.05^{\mathrm{BCD} / \mathrm{A}}$ & 0.24 & $1.86^{\mathrm{AB} / \mathrm{A}}$ & 0.17 & $1.93^{\mathrm{AB} / \mathrm{A}}$ & 0.08 & $2.61^{\mathrm{CD} / \mathrm{B}}$ & 0.02 & $2.91^{\mathrm{CD} / \mathrm{B}}$ & 0.26 \\
\hline $90: 10 \mathrm{~N}_{2}: \mathrm{CO}_{2}$ & $2.26^{\mathrm{D} / \mathrm{B}}$ & 0.17 & $1.58^{\mathrm{A} / \mathrm{A}}$ & 0.43 & $2.20^{\mathrm{BC} / \mathrm{B}}$ & 0.25 & $2.81^{\mathrm{D} / \mathrm{C}}$ & 0.19 & $3.61^{\mathrm{E} / \mathrm{D}}$ & 0.34 \\
\hline $80: 20 \mathrm{O}_{2}: \mathrm{N}_{2}$ & $2.16^{\mathrm{CD} / \mathrm{A}}$ & 0.14 & $2.51^{\mathrm{C} / \mathrm{A}}$ & 0.22 & $2.49^{\mathrm{C} / \mathrm{A}}$ & 0.09 & $2.55^{\mathrm{CD} / \mathrm{A}}$ & 0.12 & $3.35^{\mathrm{DE} / \mathrm{B}}$ & 0.27 \\
\hline $40: 30: 30 \mathrm{CO}_{2}: \mathrm{O}_{2}: \mathrm{N}_{2}$ & $1.81^{\mathrm{ABC} / \mathrm{A}}$ & 0.26 & $2.10^{\mathrm{BC} / \mathrm{AB}}$ & 0.04 & $2.16^{\mathrm{ABC} / \mathrm{AB}}$ & 0.20 & $2.05^{\mathrm{AB} / \mathrm{AB}}$ & 0.26 & $2.48^{\mathrm{AB} / \mathrm{B}}$ & 0.12 \\
\hline \multirow[t]{2}{*}{ Treatment/storage (days) } & \multicolumn{10}{|c|}{ Lactic acid bacteria (LAB) counts $\left(\log _{10} \mathrm{CFU} / \mathrm{cm}^{2}\right)$} \\
\hline & 7 & S.E & 9 & S.E & 11 & S.E & 14 & S.E & 17 & S.E \\
\hline Control & $4.18^{\mathrm{D} / \mathrm{E}}$ & 0.21 & $5.43^{\mathrm{E} / \mathrm{F}}$ & 0.10 & $6.15^{\mathrm{D} / \mathrm{G}}$ & 0.22 & $6.51^{\mathrm{E} / \mathrm{G}}$ & 0.29 & $6.49^{\mathrm{BC} / \mathrm{G}}$ & 0.13 \\
\hline $10: 90 \mathrm{~N}_{2}: \mathrm{CO}_{2}$ & $2.91^{\mathrm{AB} / \mathrm{C}}$ & 0.08 & $3.45^{\mathrm{A} / \mathrm{D}}$ & 0.05 & $3.68^{\mathrm{A} / \mathrm{D}}$ & 0.16 & $4.14^{\mathrm{A} / \mathrm{E}}$ & 0.43 & $5.08^{\mathrm{A} / \mathrm{F}}$ & 0.37 \\
\hline $30: 70 \mathrm{~N}_{2}: \mathrm{CO}_{2}$ & $2.56^{\mathrm{A} / \mathrm{D}}$ & 0.17 & $3.78^{\mathrm{AB} / \mathrm{E}}$ & 0.12 & $4.29^{\mathrm{AB} / \mathrm{F}}$ & 0.14 & $4.38^{\mathrm{A} / \mathrm{F}}$ & 0.24 & $5.38^{\mathrm{A} / \mathrm{G}}$ & 0.20 \\
\hline $50: 50 \mathrm{~N}_{2}: \mathrm{CO}_{2}$ & $2.84^{\mathrm{AB} / \mathrm{D}}$ & 0.16 & $4.00^{\mathrm{AB} / \mathrm{E}}$ & 0.04 & $4.85^{\mathrm{BC} / \mathrm{F}}$ & 0.42 & $5.57^{\mathrm{BC} / \mathrm{G}}$ & 0.13 & $5.93^{\mathrm{B} / \mathrm{G}}$ & 0.08 \\
\hline $70: 30 \mathrm{~N}_{2}: \mathrm{CO}_{2}$ & $3.40^{\mathrm{C} / \mathrm{C}}$ & 0.21 & $4.60^{\mathrm{BC} / \mathrm{D}}$ & 0.12 & $5.45^{\mathrm{CD} / \mathrm{E}}$ & 0.10 & $6.06^{\mathrm{D} / \mathrm{F}}$ & 0.11 & $6.42^{\mathrm{CD} / \mathrm{F}}$ & 0.08 \\
\hline $90: 10 \mathrm{~N}_{2}: \mathrm{CO}_{2}$ & $4.25^{\mathrm{D} / \mathrm{E}}$ & 0.16 & $4.94^{\mathrm{CD} / \mathrm{F}}$ & 0.29 & $5.83^{\mathrm{D} / \mathrm{G}}$ & 0.12 & $5.96^{\mathrm{CD} / \mathrm{G}}$ & 0.05 & $6.94^{\mathrm{D} / \mathrm{H}}$ & 0.53 \\
\hline $80: 20 \mathrm{O}_{2}: \mathrm{N}_{2}$ & $4.08^{\mathrm{D} / \mathrm{C}}$ & 0.10 & $5.37^{\mathrm{DE} / \mathrm{D}}$ & 0.05 & $5.43^{\mathrm{CD} / \mathrm{D}}$ & 0.15 & $6.29^{\mathrm{DE} / \mathrm{E}}$ & 0.29 & $6.78^{\mathrm{CD} / \mathrm{F}}$ & 0.18 \\
\hline $40: 30: 30 \mathrm{CO}_{2}: \mathrm{O}_{2}: \mathrm{N}_{2}$ & $3.21^{\mathrm{BC} / \mathrm{C}}$ & 0.24 & $3.95^{\mathrm{AB} / \mathrm{D}}$ & 0.16 & $4.74^{\mathrm{BC} / \mathrm{E}}$ & 0.44 & $5.33^{\mathrm{B} / \mathrm{F}}$ & 0.15 & $6.25^{\mathrm{BC} / \mathrm{G}}$ & 0.21 \\
\hline
\end{tabular}

${ }^{\mathrm{a}}$ S.E. = standard error; $\mathrm{X} / \mathrm{Y}, \mathrm{X}=$ Comparisons were made between treatments for a sampling stage, $\mathrm{Y}=$ Comparisons made between days. The same letter indicates not statistically different at the $5 \%$ level $(P>0.05)$.

excess of 17 days with $\mathrm{CO}_{2}$ concentrations higher than $50 \%$. Chouliara et al. (2007) observed a 6 day shelf-life in air packs which was extended by 3 and 7 days using 30:70\% and 70:30\% $\mathrm{CO}_{2}: \mathrm{N}_{2}$, respectively. Boysen et al. (2007) also found higher $\mathrm{CO}_{2}$ concentrations were more effective at inhibiting bacterial growth on raw poultry and reported a shelf-life in excess of 20 days at $4{ }^{\circ} \mathrm{C}$ with $60: 40 \%$ and $90: 10 \% \mathrm{CO}_{2}: \mathrm{N}_{2}$.

After 9 days at $2{ }^{\circ} \mathrm{C}$ the Pseudomonas counts were $3.7-4.5 \log _{10}$ $\mathrm{CFU} / \mathrm{cm}^{2}$ lower in packs containing $30-50 \% \mathrm{CO}_{2}$, considerably higher than the $1.1-2.1 \log _{10} \mathrm{CFU} / \mathrm{cm}^{2}$ reduction previously reported by Chouliara et al. (2007) for raw poultry stored at $4{ }^{\circ} \mathrm{C}$ under the same atmospheric conditions. Regardless, these studies show that gaseous combinations of $\mathrm{CO}_{2}$ and $\mathrm{N}_{2}$ without $\mathrm{O}_{2}$ significantly inhibit the growth of Pseudomonas, the main spoilage organisms in meat (Jay, 1986). This study therefore provides more evidence that $\mathrm{CO}_{2}$ retards the growth of aerobic spoilage bacteria as a result of an extension of the lag phase and a decreased growth rate during the logarithmic phase of growth as has been previously suggested
(Farber, 1991). Indeed if $10^{7-8} \mathrm{CFU} / \mathrm{cm}^{-2}$ Pseudomonas was used as the indicator of the end of shelf-life as suggested by Nychas et al. (2008) and Charles et al. (2006), all of the packs with $30 \%$ or higher $\mathrm{CO}_{2}$ concentrations showed a shelf-life extension in excess of 10 days. This effect has been attributed to Pseudomonas being strict aerobes, thus requiring $\mathrm{O}_{2}$ for metabolism and growth. However, significant growth was still observed in this and other studies (Patsias et al., 2006a,b) in packs without added $\mathrm{O}_{2}$, suggesting the transmission of $\mathrm{O}_{2}$, all-be-it at low levels, across the packaging film. It is also worth noting that low $\mathrm{O}_{2}$ concentrations were not the only factor inhibiting Pseudomonas growth in our study as fillets packed in $40: 30: 30 \% \mathrm{CO}_{2}: \mathrm{O}_{2}: \mathrm{N}_{2}$ had significantly lower counts from 4 days onwards as compared to the control packs.

To the best of our knowledge this is the first study to measure the concentration of dissolved $\mathrm{CO}_{2}$ in chicken fillets using a range of different gaseous combinations and over time during chilled storage. In packs with a $\mathrm{CO}_{2}$ concentration of $30 \%$ or higher, most of the dissolution into the chicken fillet occurred in the first $24 \mathrm{~h}$ although

Table 6

Mean Pseudomonas counts $\left(\log _{10} \mathrm{CFU} / \mathrm{cm}^{2}\right)$ on chicken fillets packed in different MAP gaseous combinations over the course of 17 days storage at $2{ }^{\circ} \mathrm{C}$.

\begin{tabular}{|c|c|c|c|c|c|c|c|c|c|c|}
\hline \multirow[t]{2}{*}{ Treatment/storage (days) } & \multicolumn{10}{|c|}{ Pseudomonas counts $\left(\log _{10} \mathrm{CFU} / \mathrm{cm}^{2}\right)$} \\
\hline & 1 & S.E $\mathrm{E}^{\mathrm{a}}$ & 2 & S.E & 3 & S.E & 4 & S.E & 5 & S.E \\
\hline Control & $2.71^{\mathrm{A} / \mathrm{A}}$ & 0.15 & $3.53^{\mathrm{A} / \mathrm{AB}}$ & 0.13 & $4.07^{\mathrm{A} / \mathrm{ABC}}$ & 0.47 & $4.87^{\mathrm{C} / \mathrm{BC}}$ & 0.12 & $5.37^{\mathrm{C} / \mathrm{CD}}$ & 0.32 \\
\hline $10: 90 \mathrm{~N}_{2}: \mathrm{CO}_{2}$ & $2.19^{\mathrm{A} / \mathrm{A}}$ & 0.14 & $2.85^{\mathrm{A} / \mathrm{A}}$ & 0.12 & $2.38^{\mathrm{A} / \mathrm{A}}$ & 0.34 & $2.77^{\mathrm{A} / \mathrm{A}}$ & 0.27 & $2.16^{\mathrm{A} / \mathrm{A}}$ & 0.84 \\
\hline $30: 70 \mathrm{~N}_{2}: \mathrm{CO}_{2}$ & $2.57^{\mathrm{A} / \mathrm{A}}$ & 0.49 & $2.11^{\mathrm{A} / \mathrm{A}}$ & 0.30 & $2.42^{\mathrm{A} / \mathrm{A}}$ & 0.25 & $2.82^{\mathrm{A} / \mathrm{A}}$ & 0.18 & $2.67^{\mathrm{A} / \mathrm{A}}$ & 0.42 \\
\hline $50: 50 \mathrm{~N}_{2}: \mathrm{CO}_{2}$ & $2.07^{\mathrm{A} / \mathrm{A}}$ & 0.10 & $2.39^{\mathrm{A} / \mathrm{A}}$ & 0.04 & $2.53^{\mathrm{A} / \mathrm{A}}$ & 0.18 & $2.89^{\mathrm{AB} / \mathrm{A}}$ & 0.11 & $2.70^{\mathrm{A} / \mathrm{A}}$ & 0.27 \\
\hline $70: 30 \mathrm{~N}_{2}: \mathrm{CO}_{2}$ & $2.90^{\mathrm{A} / \mathrm{A}}$ & 0.40 & $3.00^{\mathrm{A} / \mathrm{A}}$ & 0.21 & $2.32^{\mathrm{A} / \mathrm{A}}$ & 0.21 & $3.38^{\mathrm{ABC} / \mathrm{AB}}$ & 0.23 & $3.22^{\mathrm{AB} / \mathrm{A}}$ & 0.34 \\
\hline $90: 10 \mathrm{~N}_{2}: \mathrm{CO}_{2}$ & $2.70^{\mathrm{A} / \mathrm{A}}$ & 0.18 & $3.08^{\mathrm{A} / \mathrm{AB}}$ & 0.16 & $3.34^{\mathrm{A} / \mathrm{ABC}}$ & 0.36 & $4.22^{\mathrm{ABC} / \mathrm{BCD}}$ & 0.16 & $4.87^{\mathrm{BC} / \mathrm{CD}}$ & 0.23 \\
\hline $80: 20 \mathrm{O}_{2}: \mathrm{N}_{2}$ & $2.50^{\mathrm{A} / \mathrm{A}}$ & 0.09 & $3.35^{\mathrm{A} / \mathrm{AB}}$ & 0.06 & $4.11^{\mathrm{A} / \mathrm{BC}}$ & 0.27 & $4.47^{\mathrm{BC} / \mathrm{BC}}$ & 0.15 & $5.47^{\mathrm{C} / \mathrm{DE}}$ & 0.62 \\
\hline $40: 30: 30 \mathrm{CO}_{2}: \mathrm{O}_{2}: \mathrm{N}_{2}$ & $2.26^{\mathrm{A} / \mathrm{A}}$ & 0.22 & $2.83^{\mathrm{A} / \mathrm{A}}$ & 0.07 & $2.62^{\mathrm{A} / \mathrm{A}}$ & 0.26 & $3.13^{\mathrm{AB} / \mathrm{A}}$ & 0.17 & $3.38^{\mathrm{AB} / \mathrm{AB}}$ & 0.70 \\
\hline \multirow[t]{2}{*}{ Treatment/storage (days) } & \multicolumn{10}{|c|}{ Pseudomonas counts $\left(\log _{10} \mathrm{CFU} / \mathrm{cm}^{2}\right)$} \\
\hline & 7 & S.E & 9 & S.E & 11 & S.E & 14 & S.E & 17 & S.E \\
\hline Control & $6.83^{\mathrm{C} / \mathrm{D}}$ & 0.12 & $9.25^{\mathrm{D} / \mathrm{E}}$ & 0.07 & $9.83^{\mathrm{D} / \mathrm{EF}}$ & 0.18 & $11.15^{\mathrm{C} / \mathrm{F}}$ & 0.50 & $10.49^{\mathrm{D} / \mathrm{EF}}$ & 0.27 \\
\hline $10: 90 \mathrm{~N}_{2}: \mathrm{CO}_{2}$ & $4.74^{\mathrm{AB} / \mathrm{B}}$ & 0.41 & $6.27^{\mathrm{AB} / \mathrm{C}}$ & 0.35 & $5.47^{\mathrm{AB} / \mathrm{BC}}$ & 0.15 & $6.11^{\mathrm{AB} / \mathrm{BC}}$ & 0.43 & $5.95^{\mathrm{AB} / \mathrm{BC}}$ & 0.34 \\
\hline $30: 70 \mathrm{~N}_{2}: \mathrm{CO}_{2}$ & $3.57^{\mathrm{A} / \mathrm{AB}}$ & 0.72 & $5.59^{\mathrm{A} / \mathrm{C}}$ & 0.49 & $5.28^{\mathrm{A} / \mathrm{C}}$ & 0.57 & $4.54^{\mathrm{A} / \mathrm{BC}}$ & 0.67 & $4.80^{\mathrm{A} / \mathrm{BC}}$ & 0.51 \\
\hline $50: 50 \mathrm{~N}_{2}: \mathrm{CO}_{2}$ & $3.55^{\mathrm{A} / \mathrm{AB}}$ & 0.58 & $4.65^{\mathrm{A} / \mathrm{BC}}$ & 0.42 & $4.98^{\mathrm{A} / \mathrm{BC}}$ & 0.40 & $5.11^{\mathrm{A} / \mathrm{C}}$ & 0.31 & $4.53^{\mathrm{A} / \mathrm{BC}}$ & 0.28 \\
\hline $70: 30 \mathrm{~N}_{2}: \mathrm{CO}_{2}$ & $3.40^{\mathrm{A} / \mathrm{AB}}$ & 0.33 & $4.78^{\mathrm{A} / \mathrm{BC}}$ & 0.24 & $5.13^{\mathrm{A} / \mathrm{C}}$ & 0.24 & $5.39^{\mathrm{A} / \mathrm{C}}$ & 0.13 & $5.77^{\mathrm{AB} / \mathrm{C}}$ & 0.07 \\
\hline $90: 10 \mathrm{~N}_{2}: \mathrm{CO}_{2}$ & $5.25^{\mathrm{BC} / \mathrm{D}}$ & 0.22 & $7.54^{\mathrm{BC} / \mathrm{E}}$ & 0.63 & $6.98^{\mathrm{BC} / \mathrm{E}}$ & 0.26 & $7.16^{\mathrm{B} / \mathrm{E}}$ & 0.29 & $7.77^{\mathrm{C} / \mathrm{E}}$ & 0.54 \\
\hline $80: 20 \mathrm{O}_{2}: \mathrm{N}_{2}$ & $6.31^{\mathrm{BC} / \mathrm{E}}$ & 0.47 & $8.04^{\mathrm{CD} / \mathrm{F}}$ & 0.58 & $8.47^{\mathrm{CD} / \mathrm{FG}}$ & 0.30 & $9.98^{\mathrm{C} / \mathrm{GH}}$ & 0.32 & $10.54^{\mathrm{D} / \mathrm{H}}$ & 0.50 \\
\hline $40: 30: 30 \mathrm{CO}_{2}: \mathrm{O}_{2}: \mathrm{N}_{2}$ & $4.90^{\mathrm{AB} / \mathrm{BC}}$ & 0.97 & $4.99^{\mathrm{A} / \mathrm{C}}$ & 0.61 & $5.17^{\mathrm{A} / \mathrm{CD}}$ & 0.15 & $5.31^{\mathrm{A} / \mathrm{CD}}$ & 0.51 & $6.56^{\mathrm{BC} / \mathrm{D}}$ & 0.31 \\
\hline
\end{tabular}

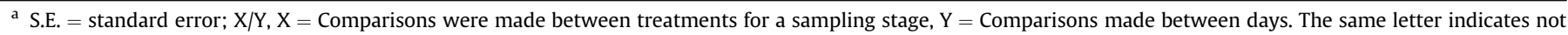
statistically different at the $5 \%$ level $(P>0.05)$. 


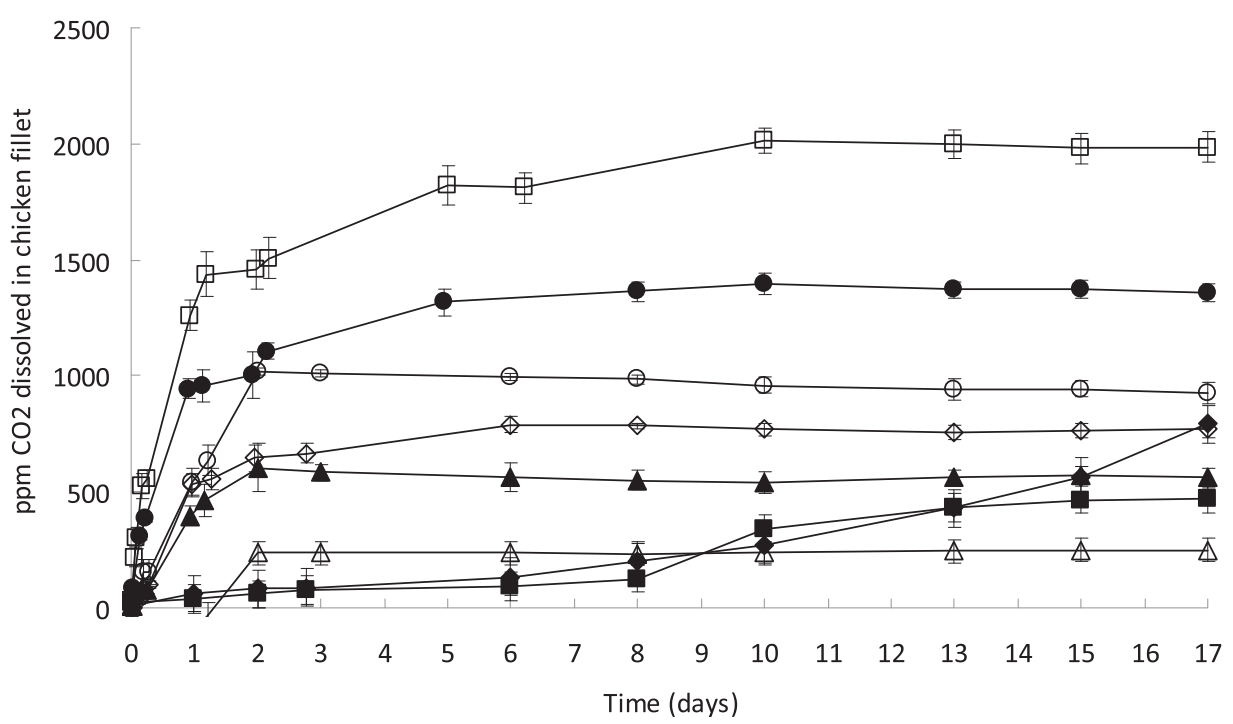

Fig. 1. Dissolved $\mathrm{CO}_{2}$ (ppm) in poultry fillets stored at $2{ }^{\circ} \mathrm{C}$ over 17 days in modified atmospheres; with ( $\left.\mathrm{N}_{2}: \mathrm{CO}_{2} ; \triangle 90: 10 \% \mathrm{~N}_{2}: \mathrm{CO}_{2} ; \diamond 80: 20 \% \mathrm{O}_{2}: \mathrm{N}_{2} ; \diamond 40: 30: 30 \% \mathrm{CO}_{2}: \mathrm{O}_{2}: \mathrm{N}_{2}\right)$.

it required 2-7 days before an equilibrium was achieved, at levels directly related to the original concentration of $\mathrm{CO}_{2}$ in the pack. It has been previously established that $\mathrm{CO}_{2}$ in MAP is absorbed by water and lipids in the food until an equilibrium or saturation is
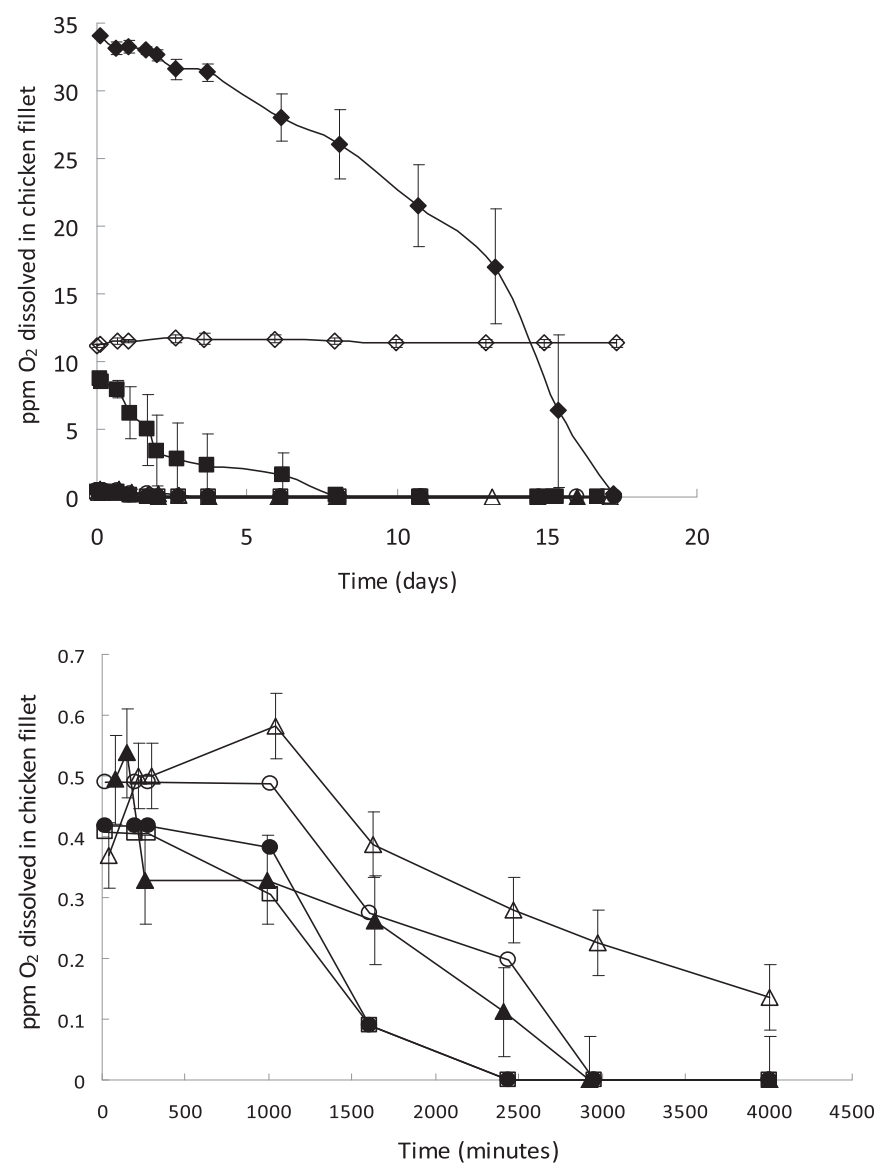

Fig. 2. Dissolved $\mathrm{O}_{2}(\mathrm{ppm})$ in poultry fillets stored at $2{ }^{\circ} \mathrm{C}$ over 17 days in modified atmospheres; with ( control, a10:90\% $\mathrm{N}_{2}: \mathrm{CO}_{2} ;-30: 70 \% \mathrm{~N}_{2}: \mathrm{CO}_{2} ; 50: 50 \% \mathrm{~N}_{2}: \mathrm{CO}_{2}$; \ 70:30\% $\left.\mathrm{N}_{2}: \mathrm{CO}_{2} ; \triangle 90: 10 \% \mathrm{~N}_{2}: \mathrm{CO}_{2} ; \diamond 80: 20 \% \mathrm{O}_{2}: \mathrm{N}_{2} ; \diamond 40: 30: 30 \% \mathrm{CO}_{2}: \mathrm{O}_{2}: \mathrm{N}_{2}\right)$. achieved (Jakobsen and Bertelsen, 2006). The high rate of $\mathrm{CO}_{2}$ absorption into poultry during the first day's storage has been previously reported (Rotabakk et al., 2010; Al-Nehlawi et al., 2013). AlNehlawi et al. (2013) observed an average of $567 \mathrm{ppm} \mathrm{CO}_{2}$ dissolved into a chicken drumstick after $24 \mathrm{~h}$ in packs containing 70:15:15\% $\mathrm{CO}_{2}: \mathrm{O}_{2}: \mathrm{N}_{2}$ and stored at $3{ }^{\circ} \mathrm{C}$, which is similar to our observations with 40:30:30\% $\quad \mathrm{CO}_{2}: \mathrm{O}_{2}: \mathrm{N}_{2}$. Rotabakk et al. (2010) obtained $450 \mathrm{ppm} \mathrm{CO} 2$ in chicken fillets after $120 \mathrm{~min}$ in $100 \% \mathrm{CO}_{2}$, well within the range of $303 \mathrm{ppm}$ (102 $\mathrm{min}$ ) and 525 (257 min) observed in this study with $10: 90 \% \mathrm{~N}_{2}: \mathrm{CO}_{2}$.

Using the volumetric method to estimate the amount of dissolved $\mathrm{CO}_{2}$ in semi rigid trays has some limitations (Rotabakk et al., 2007) as the semi-rigid trays do not allow for an exact measurement of the amount of gases in the atmosphere because part of the decrease on partial pressure is absorbed by the rigid behaviour of the package. Thus changes in the volume are affected, leading to an underestimation of dissolved gas in the food product. To protect against this a g/p-ratio was 5:1 was used in the present studies and a second method (Henrys constant method) was also used to estimate the concentration of dissolved $\mathrm{CO}_{2}$. The similarity of results (day 3 to day 5-6) obtained using the two methods suggested that using the higher $\mathrm{g} / \mathrm{p}$ ratio was effective in overcoming any issues with tray rigidity.

There is a clear connection between the observed decrease in $\mathrm{O}_{2}$ and corresponding increase in $\mathrm{CO}_{2}$ in the packs with 80:20 $\mathrm{O}_{2}: \mathrm{N}_{2}$ (Figs. 1 and 2). The same phenomenon was also observed in the control packs. This is most likely caused by the growth of aerobic bacteria, resulting in the consumption of $\mathrm{O}_{2}$ and the production of $\mathrm{CO}_{2}$ (Boskou and Debevere, 1997; Fletcher et al., 2002). Although the changes in head space gas composition changed due to microbial metabolic activity, the poultry samples were still in equilibrium with the surrounding gas as described by Henry's law.

Enterobacteriaceae also grew on poultry fillets packed in the different atmospheric gaseous combinations but significantly reduced growth was observed in packs containing $30 \%$ or more $\mathrm{CO}_{2}$. This slower rate of growth in the absence of $\mathrm{O}_{2}$ has been previously reported on poultry (Chouliara et al., 2007) and is in agreement with the results of Rajkovic et al. (2010), Boysen et al. (2007) and Gill et al. (1990). This and the other data presented in this study support the application of gaseous mixtures containing 30-90\% $\mathrm{CO}_{2}$ with the balance as $\mathrm{N}_{2}$ to inhibit bacteria growth and extend 
the shelf-life of fresh chicken fillets. It also shows that these gaseous combinations support the survival of Campylobacter which is optimally reduced in packs containing air or high levels of $\mathrm{O}_{2}$. However, a compromise mixture containing 40:30:30\% $\mathrm{CO}_{2}: \mathrm{O}_{2}: \mathrm{N}_{2}$ will achieve the extended shelf-life without promoting the maintenance of Campylobacter and this mixture should be used in the poultry industry.

\section{Conclusions}

Although the application of higher $\mathrm{CO}_{2}$ concentrations in MAP increases shelf-life, $50 \%$ is as effective as $90 \%$ at controlling TVC, TEC and Pseudomonas on chicken fillets stored at $2{ }^{\circ} \mathrm{C}$, while $70 \%$ was as effective as the higher concentration for LAB. 40:30:30 $\mathrm{CO}_{2}: \mathrm{O}_{2}: \mathrm{N}_{2}$, was the most appropriate gaseous mixture for achieving the dual objectives of extending shelf-life while inhibiting Campylobacter survival. The data presented in this and related studies should provide the basis for new microbial models that will predict microbial growth and shelf-life of poultry fillets stored under different MAP conditions thus facilitating a more scientific approach to pathogen control and reduced waste in the poultry industry.

\section{Acknowledgements}

This research was funded by the Food Institutional Research Measure (FIRM), administered by the Department of Agriculture, Food and the Marine (DAFM), Ireland. The authors also acknowledge Ms Paula Reid for statistical analysis of the data. Part of this work is supported by the project "Innovative and Safe Seafood Processing, Hygiene, Spectroscopy" funded by the Research Council of Norway (NFR project no. 186905).

\section{References}

Al-Nehlawi, A., Saldo, J., Vega, L.F., Guri, S., 2013. Effect of high carbon dioxide atmosphere packing and soluble gas stabilization pre-treatment on the shelf-life and quality of chicken drumsticks. Meat Sci. 94 (1), 1-8.

Boskou, G., Debevere, J., 1997. Reduction of trimethylamine oxide by Shewanella spp. under modified atmospheres in vitro. Food Microbiol. 14 (6), 543-553.

Boysen, L., Knochel, S., Rosenquist, H., 2007. Survival of Campylobacter jejuni in different gas mixtures. FEMS Microbiol. Lett. 266 (2), 152-157.

Byrd, J.A., Sams, A.R., Hargis, B.M., Caldwell, D.J., 2011. Effect of selected modified atmosphere packing on Campylobacter survival in raw poultry. Poult. Sci. 90 (6), 1324-1328.

Carroll, J.J., Slupsky, J.D., Mather, A.E., 1991. The solubility of carbon dioxide in water at low pressure. J. Phys. Chem. Ref. Data 20 (6), 1201-1209.

Charles, N., Williams, S.K., Rodrick, G.E., 2006. Effects of packaging systems on the natural microflora and acceptability of chicken breast meat. Poult. Sci. 85 (10), $1798-1801$.

Chouliara, E., Karatapanis, A Savvaidis, IN Kontominas, M.G, 2007. Combined effect of oregano essential oil and modified atmosphere packing on shelf-life extension of fresh chicken breast meat, stored at $4^{\circ} \mathrm{C}$. Food Microbiol. 24 (6) 607-617.

Devlieghere, F., Debevere, J., 2000. Influence of dissolved carbon dioxide on the growth of spoilage bacteria. Food Sci. Technol. 33 (8), 531-537.

Devlieghere, F., Debevere, J., van Impe, J., 1998. Concentration of carbon dioxide in the water-phase as a parameter to model the effect of a modified atmosphere on microorganisms. Int. J. Food Microbiol. 43 (1-2), 105-113.

European Food Safety Authority (EFSA), 2010. Analysis of the baseline survey on the prevalence of Campylobacter in broiler batches and of Campylobacter and Salmonella on broiler carcasses in the EU, 2008, Part A: Campylobacter and Salmonella prevalence estimates. EFSA J. 2010 (8), 1-100. Available online: www. efsa.europa.eu.

Farber, J.M., 1991. Microbiological aspects of modified-atmosphere packaging technology - a review. J. Food Prot. 54, 58-70.

Fletcher, G.C., Summers, G., Corrigan, V., Cumarasamy, S., Dufour, J.P., 2002. Spoilage of king salmon (Oncorhynchus tshawytscha) fillets stored under different atmospheres. J. Food Sci. 67 (6), 2362-2374.

Fletcher, G.C., Summers, G., Corrigan, V.K., Johanson, M.R., Hedderley, D., 2004. Optimizing gas mixtures for modified atmosphere packaging of fresh king salmon (Oncorhynchus tshawytscha). J. Aquat. Good Prod. Technol. 13 (4), 5-28.

Gill, C.O., 1988. The solubility of carbon dioxide in meat. Meat Sci. 22 (1), 65-71.
Gill, C.O., Harrison, J.C.L., Penney, N., 1990. The storage life of chicken carcasses packaged under carbon-dioxide. Int. J. Food Microbiol. 11 (2), 151-157.

Harvey, P., Leach, S., 1998. Analysis of coccal cell formation by Campylobacter jejuni using continuous culture techniques, and the importance of oxidative stress. J. Appl. Microbiol. 85 (2), 398-404.

Haughton, P.N., Lyng, J.G., Morgan, D.J., Cronin, D.A., Noci, F., Fanning, S., Whyte, P., 2010. An evaluation of the potential of high-intensity ultrasound for improving the microbial safety of poultry. Food Bioprocess Technol. 5 (3), 992-998.

Huat, J.T.Y., Aziz, S.A., Abu, J., Ghazali, F.M., Chilek, T.Z.T., Ahmad, N., Sandra1, A., Nishibuchi, M., Radu, S., 2010. Thermophilic Campylobacter spp. occurrence on chickens at farm, slaughter house and retail. Int. J. Poult. Sci. 9 (2), 134-138.

International Commission on Microbiological Specifications for Foods (ICMSF), 1986. In: Microorganisms in Foods. Sampling for Microbiological Analysis: Principles and Scientific Applications, second ed., vol. 2. University of Toronto Press, Toronto, pp. 181-196.

Jakobsen, M., Bertelsen, G., 2004. Predicting the amount of carbon dioxide absorbed in meat. Meat Sci. 68 (4), 603-610.

Jakobsen, M., Bertelsen, G., 2006. Solubility of carbon dioxide in fat and muscletissue. J. Muscle Foods 17 (1), 9-19.

Jakobsen, M., Risbo, J., 2009. Carbon dioxide equilibrium between product and gas phase of modified atmosphere packaging systems: exemplified by semi-hard cheese. J. Food Eng. 92 (3), 285-290.

Jay, J.M., 1986. Microbial Spoilage indicators and metabolites. In: Pierson, M.D., Stern, A. (Eds.), Foodborne Microorganisms and Their Toxins. Developing Methodology. Marcel Dekker Inc., Basel, pp. 213-240.

Jimenez, S.M., Salsi, M.S., Tiburzi, M.C., Rafaghelli, R.C., Tessi, M.A., Coutaz, V.R., 1997. Spoilage microflora in fresh chicken breast stored at 4 degrees $C$ : influence of packaging methods. J. Appl. Microbiol. 83, 613-618.

Jones, D.M., Sutcliffe, E.M., Rios, R., Fox, A.J., Curry, A., 1993. Campylobacter jejuni adapts to aerobic metabolism in the environment. J. Med. Microbiol. 38 (2), 145-150.

King, D.A., Nagel, C.W., 1975. Influence of carbon dioxide upon the metabolism of Pseudomonas aeruginosa. J. Food Sci. 40 (2), 362.

Klancnik, A., Bernarda, G., Jamnik, P., Vuckovic, D., Abram, M., Smole Mozina, S., 2009. Stress response and pathogenic potential of Campylobacter jejuni cells exposed to starvation. Res. Microbiol. 160 (5), 345-352.

Nychas, G.-J.E., Skandamis, P.N., Tassou, C.C., Koutsoumanis, K.P., 2008. Meat spoilage during distribution. Meat Sci. 78 (1-2), 77-89.

Patsias, A., Chouliara, I., Paleologos, E.K., Savvaidis, I., Kontominas, M.G., 2006a. Relation of biogenic amines to microbial and sensory changes of precooked chicken meat stored aerobically and under modified atmosphere packaging at 4 degrees C. Eur. Food Res. Technol. 223 (5), 683-689.

Patsias, A., Chouliara, A., Badeka, A., savvaidis, I.N., Kontominas, M.G., 2006b. Shelflife of a chilled precooked chicken product stored in air and under modified atmospheres: microbiological, chemical, sensory attributes. Food Microbiol. 23 (5), 423-429.

Prini, R.F., Crovetto, R., 1989. Evaluation of data on solubility of simple apolar gases in light and heavy water at high temperature. J. Phys. Chem. Ref. Data 18 (3), 1231-1243.

Rajkovic, A., Tomic, N., Smigic, N., Uyttendaele, M., Ragaert, P., Devlieghere, F., 2010. Survival of Campylobacter jejuni on raw chicken legs packed in high-oxygen or high-carbon dioxide atmosphere after the decontamination with lactic acid/ sodium lactate buffer. Int. J. Food Microbiol. 140 (2-3), 201-206.

Ranson, S.L., Walker, D.A., Clarke, I.D., 1960. Effects of carbon dioxide on mitochondrial enzymes from ricinus. Biochemistry 76 (2), 216-221.

Rotabakk, B.T., Lekand, O.I., Sivertsvik, M., 2007. Volumetric method to determine carbon dioxide solubility and absorption rate in foods packaged in flexible or semi rigid package. J. Food Eng. 82 (1), 43-50.

Rotabakk, B.J., Lekang, O.-I., Siverstsvik, M., 2010. Solubility, absorption and desorption of carbon dioxide in chicken breast fillets. Food Sci. Technol. 43 (3), $442-446$.

Sade, E., Murros, A., Bjorkroth, J., 2013. Predominant enterobacteria on modifiedatmosphere packaged meat and poultry. Food Microbiol. 34 (2), 252-258.

Sears, D.F., Eisenberg, R.M., 1961. A model representing a physiological role of $\mathrm{CO}_{2}$ at the cell membrane. Genet. Eng. Biotechnol. News 44, 869.

Sivertsvik, M., Jensen, J.S., 2005. Solubility and absorption of carbon dioxide into non-respiring foods. Part 3: cooked meat products. J. Food Eng. 70 (4), 499-505.

Sivertsvik, M., Rosnes, J.T., Jeksrud, W.K., 2004. Solubility and absorption rate of carbon dioxide into non-respiring foods. Part 2: raw fish fillets. J. Food Eng. 63 (4), 451-458.

Stiles, M.E., 1991a. Scientific principles of controlled/modified atmosphere packaging. In: Ooraikul, B., Stiles, M.E. (Eds.), Modified Atmosphere Packaging of Food. Ellis Horwood Ltd., Chichester, England, pp. 18-25, 118-147.

Stiles, M.E., 1991b. Modified atmosphere packaging of meat, poultry and their products. In: Ooraikul, B., Stiles, M.E. (Eds.), Modified Atmosphere Packaging of Food. Ellis Horwood Limited, Chichester, England, pp. 118-147.

Storz, G., Imlay, J.A., 1999. Oxidative stress. Curr. Opin. Microbiol. 2, 188-194.

Thippareddi, H., Phebus, R.K., 2007. Modified atmosphere packaging (MAP): microbial control and quality. Pork Inf. Factsheet 12, 1-5.

Wolfe, S.K., 1980. Use of $\mathrm{CO}_{2}$ and $\mathrm{CO}_{2}$ enriched atmospheres for meats, fish and produce. Food Technol. 34 (3), 55-58. 